\title{
PLOIDY MANIPULATIONS FOR INTERSPECIFIC GENE TRANSFER ${ }^{1}$
}

\author{
A. K. Singh, ${ }^{2}$ J. P. Moss, ${ }^{2}$ and J. Smartt ${ }^{3}$
}

${ }^{2}$ Cytogenetics Unit, Legumes Improvement Program

International Crops Research Institute for the Semi-Arid Tropics (ICRISAT)

Patancheru P.O., Andhra Pradesh 502 324, India

${ }^{3}$ Department of Biology

University of Southampton, England

I. Introduction
II. Barriers to Interspecific Hybridization
A. Abnormal Embryo Development
B. Endosperm Disintegration.
C. Abnormal Development of Ovular Tissue

III. Diploid and Polyploid Crop Species

A. Diploid Crop Species with Diploid Wild Relatives

B. Polyploid Crop Species

IV. Application of Ploidy Manipulations

A. Increasing Crossability and Hybrid Viability

B. Manipulating Endosperm Balance Number

C: Using Unreduced (2n) Gametes

D. Providing Greater Versatility for Gene Transfer

E. Production of Hybrid and Polyploid Bridges

G. Transfer of Chromosomes, Genes, or Gene Blocks

V. Conclusions

References

\section{INTRODUCTION}

Deficiencies in crop cultigens for desirable characters, such as resistance to pests and diseases, and their availability in wild relatives are now well documented. This has led to considerable interest in interspecific breeding for effecting transfer of desirable genes from wild species into related cultigens (Watson, 1970; Knott and Dvorak, 1976; Zeven and van

'Submitted as Journal Article No. 808 by International Crops Research Institute for the Semi-Arid Tropics (ICRISAT), Patancheru P.O., Andhra Pradesh 502 324, India, and Department of Biology, University of Southampton, England. 
Harten, 1979; Stalker, 1980; Singh and Gibbons, 1985; Stalker and Moss, 1987). When the donor and the recipient species are closely related, there is usually no genetic or ploidy barrier in the production of a hybrid with a satisfactory level of chromosome paring. In such cases gene transfer can be and has been accomplished by conventional methods, such as hybridization and backcrossing. Unfortunately, a majority of wild relatives of crop species have developed reproductive isolating mechanisms which may limit interspecific hybridization or inhibit genetic introgression through lack of adequate chromosomal meiotic pairing (Hadley and Openshaw, 1980; Sastri, 1984; Singh and Gibbons, 1985). Even where pairing occurs, linkage may restrict recombination between desirable and undesirable genes and prevent production of lines with desired agronomic characters (Stalker et al., 1979).

Interspecific hybridization to incorporate alien genetic variation requires (1) the initial production and establishment of viable hybrids and (2) the subsequent integration of desirable genomic segment(s) from the donor species into the genome of the cultigen. Polyploidy has been particularly helpful in the production and propagation of many interspecific hybrid combinations with subsequent genome duplication. Similarly polyploidy has featured prominently in natural plant evolution to facilitate the establishment of populations with wider adaptability and superior potential than their parents (Stebbins, 1950, 1971; de Wet, 1980).

Incorporation of a specific desirable trait into cultivated crop species from their wild relatives involves more than the establishing an interspecific hybrid. Procedures that result in introducing only a small chromosome segment from the donor species into an acceptable genetic background of recipient species are required. Therefore, the next step in an interspecific breeding program is backcrossing to the recipient parent to incorporate one or more desirable chromosomes or chromosome segments through homologous or homoeologous chromosome pairing. If chromosome pairing is restricted, introgression of desired gene(s) from homoeologous or nonhomologous alien chromosome(s) can be achieved by encouraging homoeologous chromosome pairing between the genomes of the recipient cultigen and donor species through the manipulation of genetic control, if any, or by induced translocations.

The most successful, and therefore most frequently cited, examples of using ploidy level and chromosome manipulations for introducing alien genetic variation are from Triticum aestivum, bread wheat. These experiments have been possible because of an understanding of cytogenetic relationships between bread wheat and its wild relatives; they have led to the development of standard procedures for gene transfer by ploidy level and chromosome manipulations (Sears, 1956, 1972; Kimber and Sears, 
1980). Sears (1956) first demonstrated the role of an integrated set of manipulations in the transfer of genes conferring resistance to leaf rust (Puccinia recondita) from Aegilops umbellulata to Triticum aestivum. The present review covers situations where genetic exchange has been achieved or is possible through chromosome or ploidy manipulations of donor wild species, recipient cultivated species, or hybrids between the two. Some reported examples of ploidy manipulations in interspecific gene transfer are presented in Table I.

\section{BARRIERS TO INTERSPECIFIC HYBRIDIZATION}

Barriers to interspecific hybridization occur as a result of either sexual incompatibility or hybrid breakdown. Sexual incompatibility is caused by disharmonious pollen-pistil interaction resulting in failure of the egg to form a viable zygote. However, interspecific sexual incompatibility has not been investigated as extensively as intraspecific and self-incompatibility (Shivanna, 1982), though similar reactions have been observed in both. Hybrid breakdown, hybrid weakness; and hybrid sterility are the main crossability barriers to interspecific hybridization (Raghavan, 1986). These may be caused by arrested embryo development, endosperm disintegration, abnormal development of ovular tissue, or chromosomal or genetic instability.

\section{A. Abnormal Embryo Development}

The normal development of a hybrid embryo can be adversely affected by several factors, ranging from the action of a single deleterious gene to the action of several genes affecting development, organization, and differentiation of the hybrid embryo-besides the differences in ploidy level of the two parents. Investigations have revealed that in some cases embryo growth comes to a standstill after a particular stage, whereas in others the embryo reaches adult stage but fails to attain maturity (Shii et al., 1982). In crosses involving several related genera of Graminae, embryos succumb to the action of deleterious gene(s) at globular stage (Zenkteler and Nitzsche, 1984; Lee, 1981). Ashley (1972) observed that in crosses between Hibiscus costatus and $H$. aculeatus the cytoplasm of hybrid zygotes fail to undergo the reorganization necessary for polarization into apical and basal ends. Large vacuoles remain prominent in the cells of the dividing zygote, which finally result in a clump of highly vacuolated necrotic cells. This 


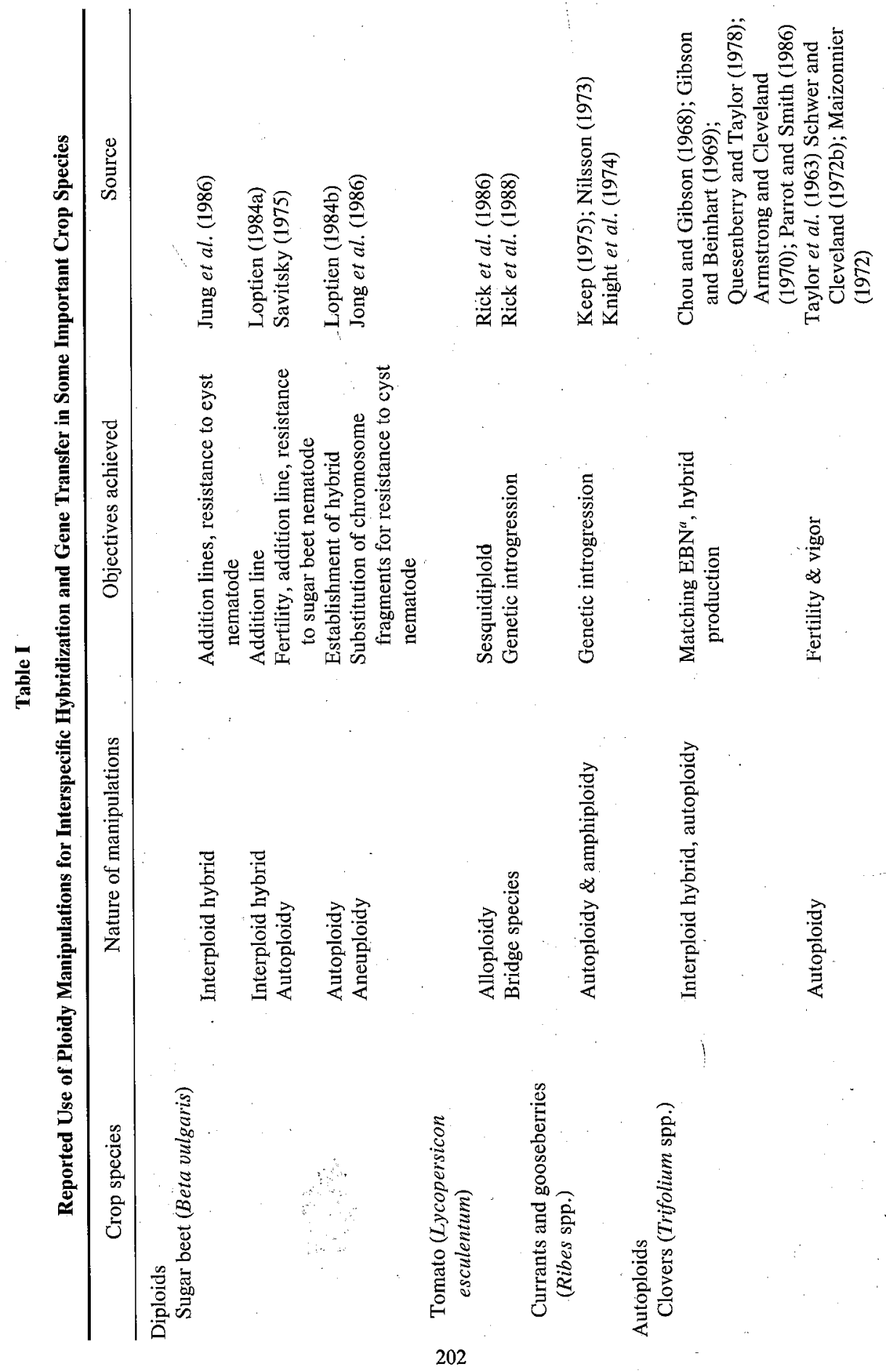




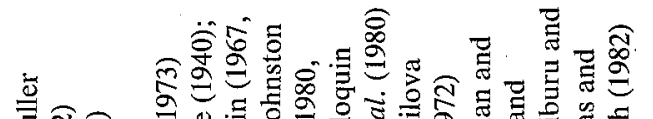

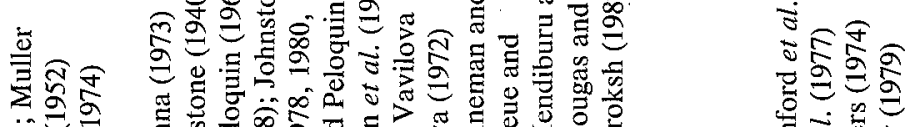

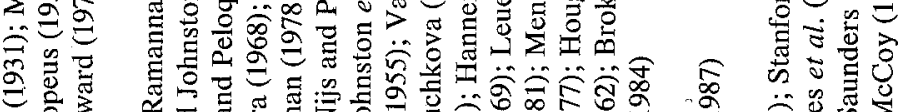

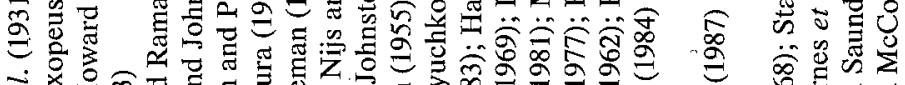

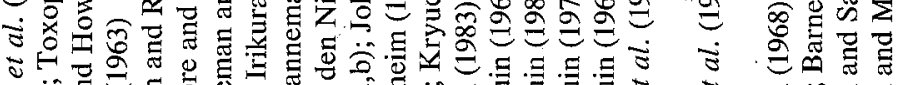

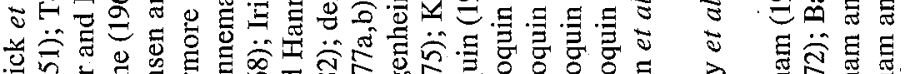

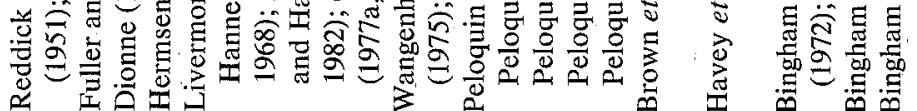
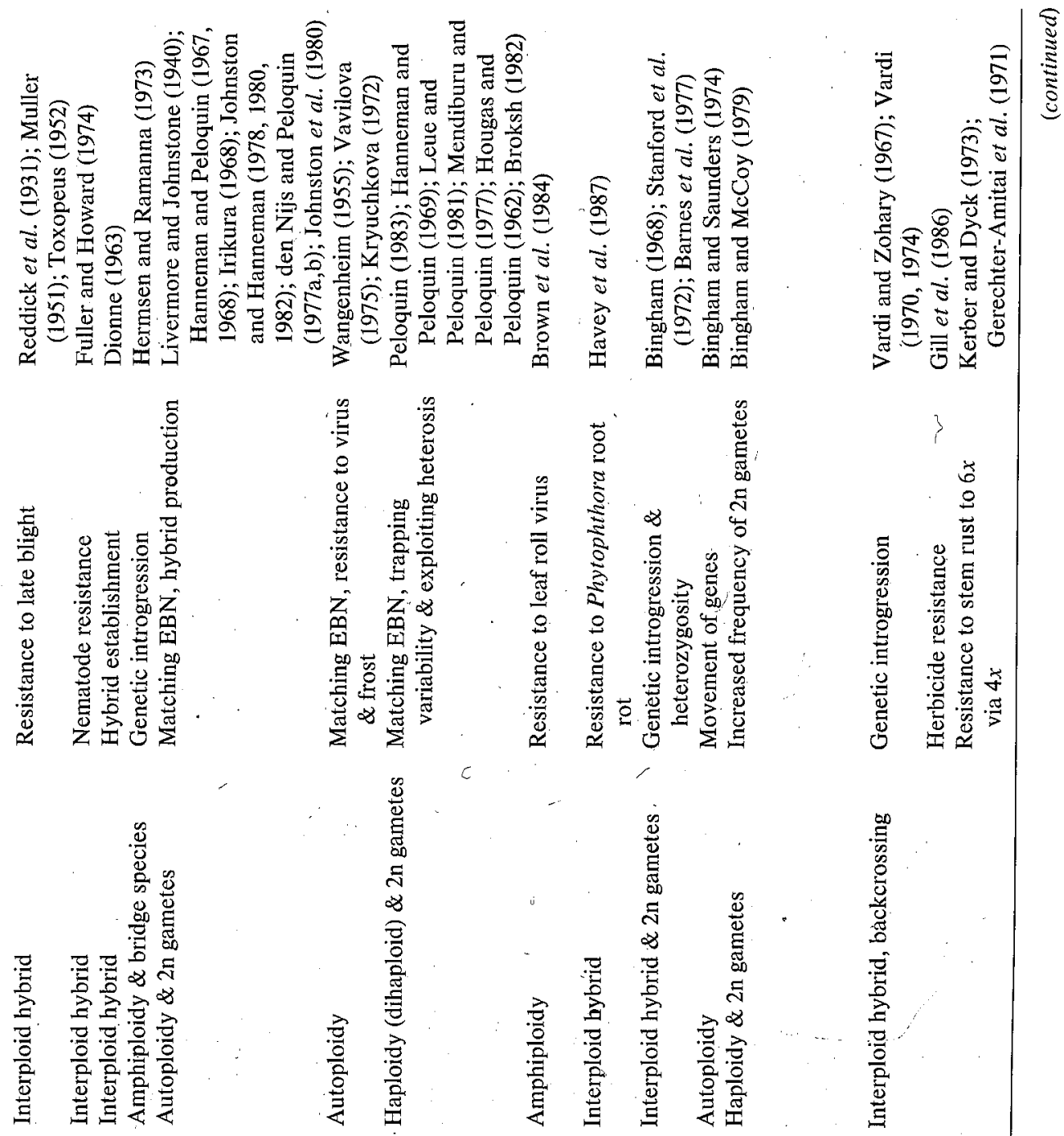

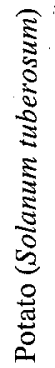

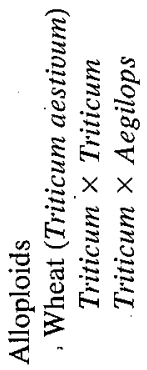




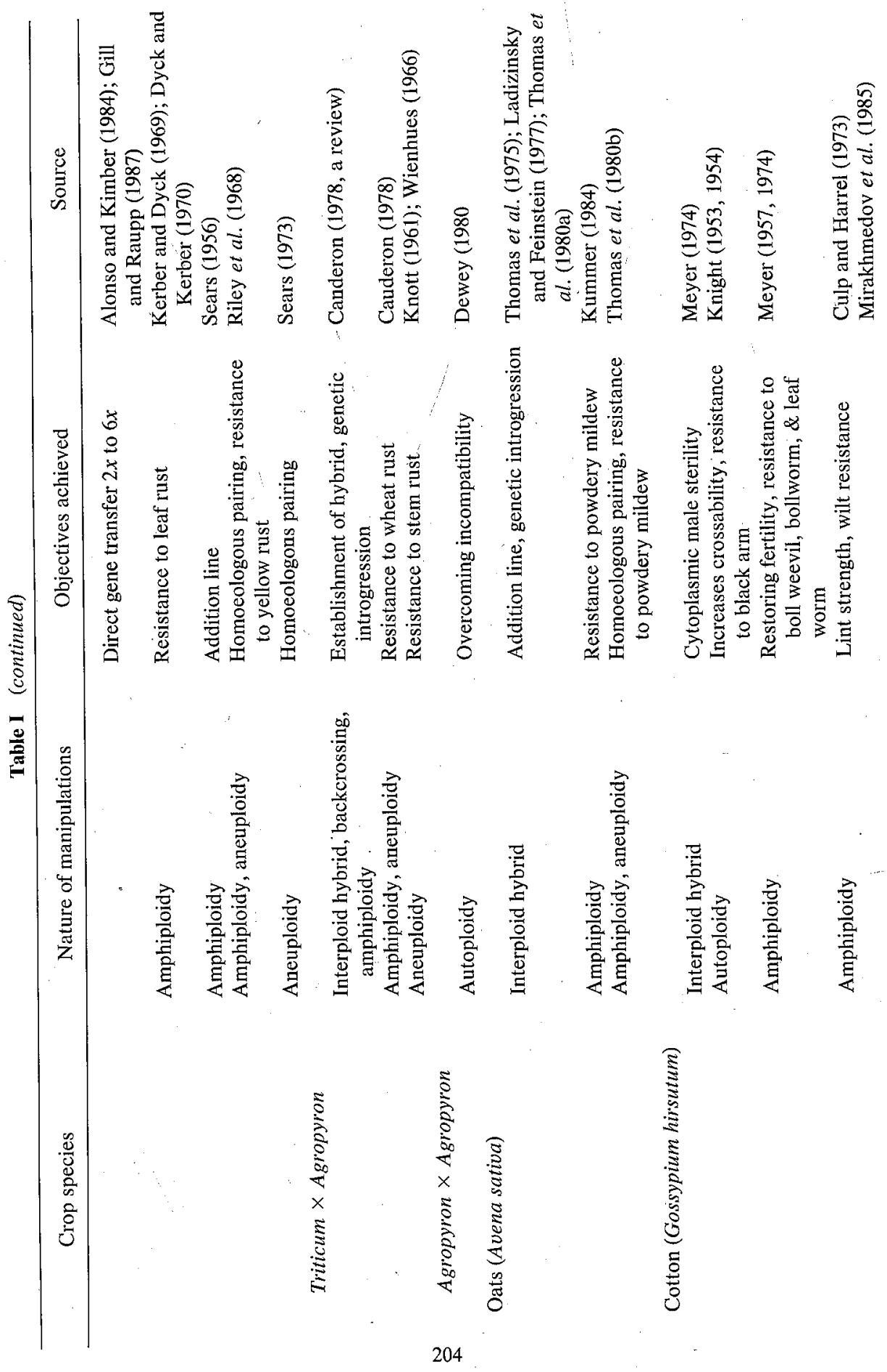




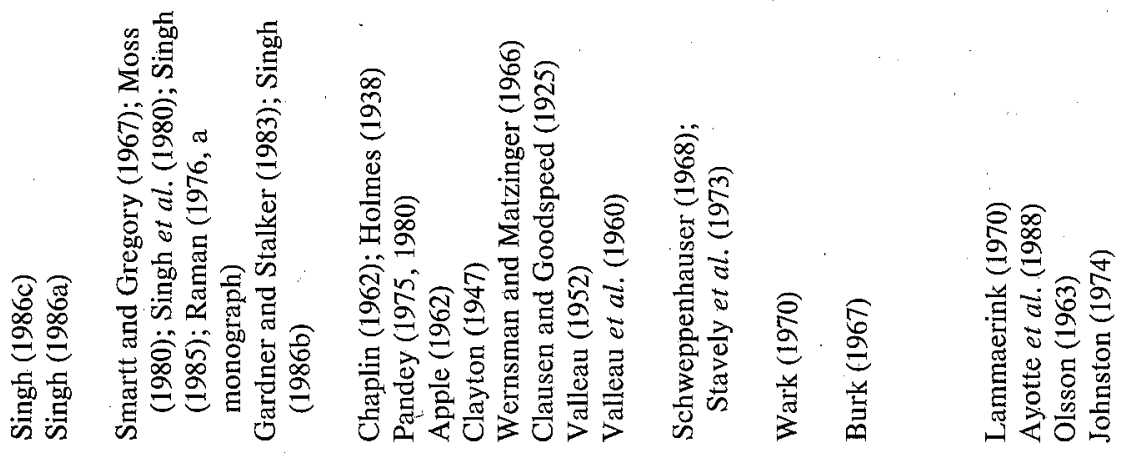

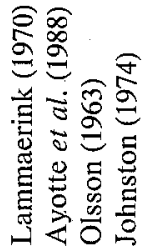

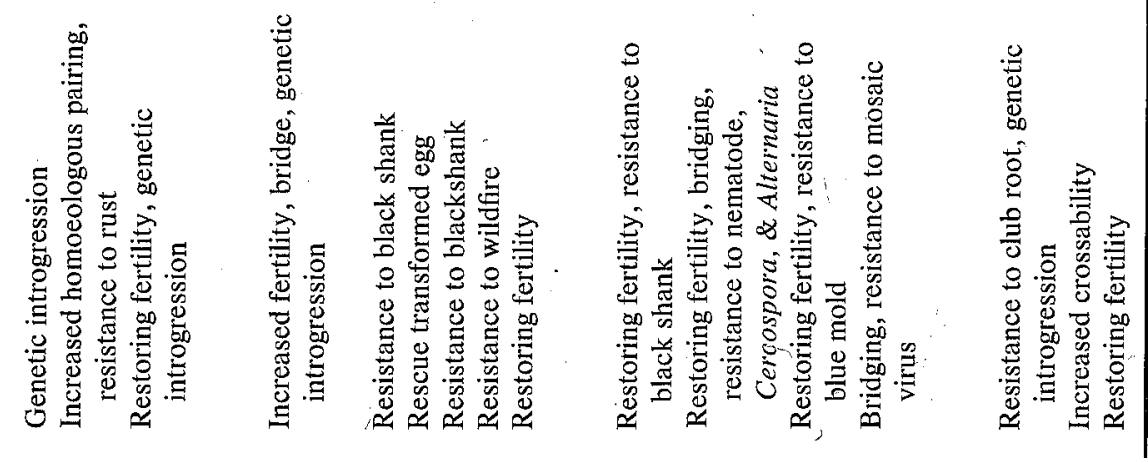

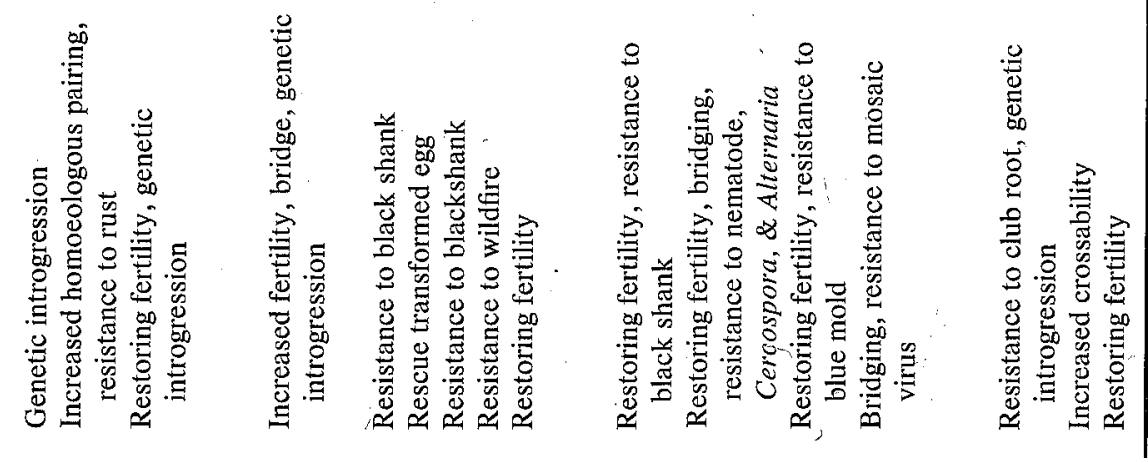

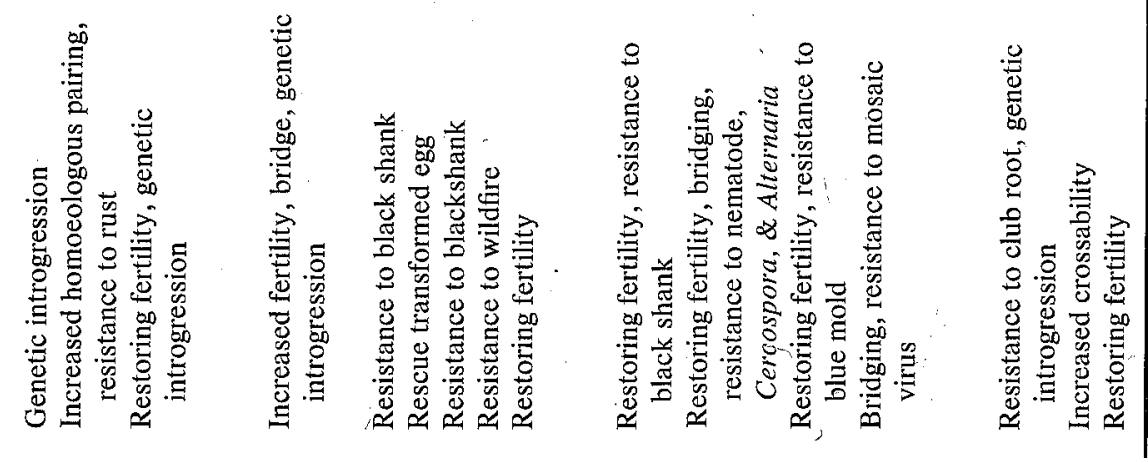

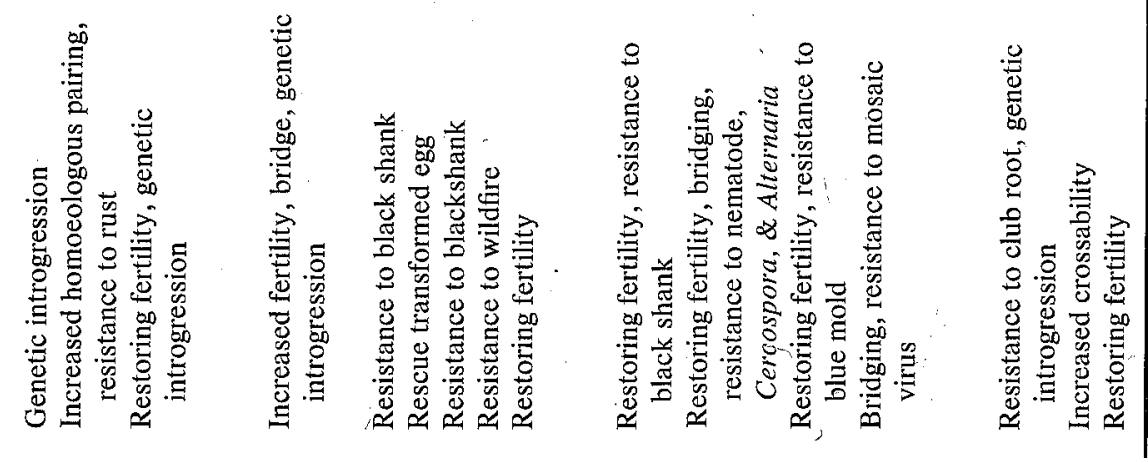

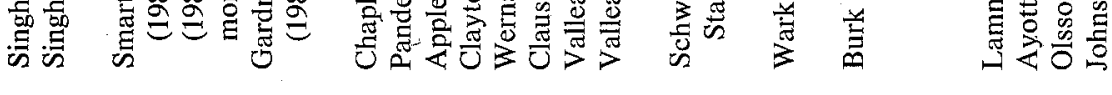

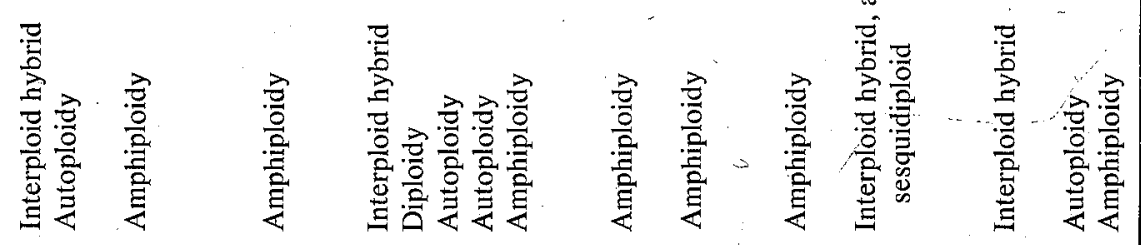

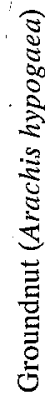

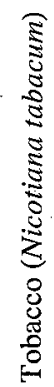

竞 
suggests that polarity and full complement of cytoplasmic organelles are essential for continued growth and differentiation of the hybrid embryo. Similarly in crosses between Medicago sativa and M. scutelata (Sangduen et al., 1983), growth of the hybrid embryo is terminated at late heart-shape stage because of the degeneration of the suspensor, cutting the nutritive supply. The suspensor of the hybrid embryo has fewer cells, with fewer plastids and less reserve starch and lipids, than the suspensor of an intraspecific embryo. It also lacks endoplasmic reticulum and microtubules and characteristic wall invaginations with transfer cell morphology mediating in metabolic exchange at the cell surface.

Inviability of the hybrid embryo can also be caused by evolutionary differences between involved species in the timing of processes such as cell division, organization, and differentiation. According to Kazimierska (1978), in Trifolium repens x T. medium mitotic activity of the hybrid embryo is slower than in the embryo of both parental species, causing abnormal development. Similarly in crosses involving members of Graminae, hybrid failure occurred as a result of disparity in the mean cell doubling times of the embryos of the two parents (Forster and Dale, 1983).

\section{B. ENDOSPERM DISINTEGRATION}

Successful development of an embryo depends on the accompanying development of endosperm tissue capable of nourishing the embryo and on harmonious interaction with maternal tissue. In interploid crosses failure of endosperm is common, and despite much research, remains an interesting and enigmatic subject. In an inviable cross disintegration of the endosperm often leads to the collapse of the embryo. A comparison between a selfed and hybrid endosperm of an interspecific cross in Trifolium has shown that the development of hybrid endosperm ceases at an early stage, limiting the synthesis of nutrients required for the growth of the embryo (Williams and White, 1976). A comparative study of cytokinin levels in the ovules of selfed Phaseolus vulgaris and hybrids between $P$. vulgaris $\times P$. acutifolius showed that cytokinin levels in the selfed endosperm were higher and correlated with the period of cell division activity of the embryo, whereas they were lower in the hybrid endosperm (Nesling and Morris, 1979). Thus, reduced cytokinin biosynthesis in hybrid endosperm causes abortion of the embryo.

Possibly the difference in dosage effects of the genes as they act in the hybrid tissue of the resultant genomic combination could account for observed success or failure in such a cross. The combination of two genomes from the female and one very different from the male may pro- 
duce unfavorable dosage effects. Such disharmony may also result from different ratios of chromosome numbers in the endosperm and embryo. Therefore, a proper balance in dosage of genes in these tissues will have to be achieved for normal development.

\section{Abnormal Development of Ovular Tissue}

Another serious disharmony resulting in embryo lethality, termed somatoplastic sterility by Cooper and Brink (1945), is associated with prolific growth of nucellus or integuments. This causes either abnormal distribution of nutrients in the seed, particularly suppressing the nutritive transport to the endosperm, which ultimately leads either to failure of the embryo to develop or to the tumor that grows into the embryo-sac finally enveloping the embryo, causing its collapse. However, since Cooper and Brink's paper it has been reported rarely, for example by Johansen and Smith (1956).

Besides these barriers, genetic introgression between the species can also be restricted as a result of production of hybrids that are either weak or sterile. Such a situation results either from chromosomal or genetic disability or disharmony between the genome of one parent and the cytoplasm of the other (DeVerna et al., 1987). Lack of pairing between the chromosomes in $F_{1}$ hybrids due to nonhomology or structural differences leads to gametes with small but significant deficiencies and duplications, which may render the gametes inviable.

\section{DIPLOID AND POLYPLOID CROP SPECIES}

On the basis of the ploidy relationships between wild and cultivated forms, Knott and Dvorak (1976) divided crop species into two broad groups: (1) diploid species with diploid wild relatives and (2) polyploid species.

\section{A. Diploid Crop Species with Diploid Wild Relatives}

This group contains species with an identical ploidy level. The genetic divergence between wild relatives and their cultivated congener can be of various degrees: (1) very little differentiation, with little restriction on crossing and chromosome pairing, as in Lycopersicon (tomato); and 
(2) substantial differentiation with strong isolating mechanisms that can restrict crossing and/or reduce chromosome pairing, as in Beta (sugar beet) and Ribes (currants and gooseberries).

\section{B. Polyploid Crop Species}

This group can be divided into two subgroups: (1) polyploid (tetraploid) crop species without an apparent diploidizing mechanism restricting homoeologous pairing, e.g., Solanum (potato), Medicago (alfalfa), or Arachis (peanut); and (2) polyploid species with an evolved diploidizing mechanism controlling chromosome pairing, e.g., Triticum, Avena (oats), Gossypium (cotton), or Nicotiana (tobacco).

In the first subgroup, induced polyploidy may help to overcome barriers to hybridization either by providing buffering capacity for acceptance of a foreign genome or by neutralizing lethal factors. In the latter subgroup, ploidy differences usually cause hybrid sterility, restricting stabilization of hybrids and genetic introgression. Many procedures have been adapted to bridge the ploidy gap, to produce fertile hybrids, and to effect gene trainsfer. The appropriate strategy for a particular species depends primarily on the genomic relationships between the species.

\section{APPLICATION OF PLOIDY MANIPULATIONS}

Changing the ploidy level of parents results in changes in gametes, fertilized ovules, and endosperm, and in a number of cases has helped in sustaining the development of the interspecific hybrid (overcoming disharmonious interactions and neutralizing lethal factors). Further, the changed genomic ratios have also altered the degree of meiotic recombinations between genomes in hybrids. We shall now consider some of these cases.

\section{A. InCreasing Crossability and Hybrid Viability}

In the case of species that do not differ in their ploidy and alleles restricting hybridization, hybridization-and therefore gene transfer-is not difficult. An illustrative example is the crossing between two Eulycopersicon species of the genus Lycopersicon-L. esculentum and $L$. pimpinellifolium (Rick and Butler, 1956)-and species of the subgenus Eriopersicon. However, interspecific gene transfer can be difficult in a 
number of instances between species even with the same chromosome number and a fair degree of chromosome homology - for example, Lycopersicon species. The apparent causes of this are genetic or cytoplasmic interactions, genetic incompatibility and sterility, and undesirable linkages (Kuriyama et al., 1971; see cryptic structural hybridity of Stebbins, 1950).

Polyploidy in such cases provides buffering capacity for introgression from foreign genomes. Outcrossing species may be more tolerant to interspecific hybridization than autogamous taxa because of their heterozygosity. Several cases have been observed where the production, viability, and fertility of hybrids between a crop species and its wild relatives have increased at higher ploidy levels. In Agropyron, attempts to hybridize diploid $A$. cristatum with diploid A. spicatum failed. Only when tetraploid races of one or both the species were used was the cross successful. Similarly, $A$. spicatum and $A$. stiplifolium could be crossed to hexaploid $A$. repens only when autotetraploid races of the former species were used (Dewey, 1980). Olsson (1963) reported that attempts to cross Brassica campestris L. $(2 n=2 x=20)$ with $B$ : oleracea $(2 n=2 x=18)$ resulted in only $16 F_{1}$ plants from 10,395 pollinations $(0.15 \%)$, whereas hybridization at the tetraploid level yielded $133 \mathrm{~F}_{1}$ plants from 22,884 pollinations $(0.58 \%)$. The reciprocal cross failed completely at the diploid level, but at the tetraploid level $130 \mathrm{~F}_{1}$ plants were obtained from 18,874 pollinations $(0.69 \%)$. Similarly attempts to produce hybrids between Trifolium pratense and $T$. diffusum at the diploid level resulted in sterile hybrids (Taylor et al., 1963; Schwer and Cleveland, 1972a). However, when the chromosome complement of $T$. diffusum was doubled and crosses made by using tetraploid $T$. pratense, crossability increased, and the resultant amphidiploids were fertile, producing viable pollen and adequate amount of seeds (Taylor et al., 1963; Schwer and Cleveland, 1972b). In this study it was suggested that these hybrids had potential as bridges for further interspecific genetic introgression. Similarly hybridization between $6 x T$. sarosiense and $2 x T$. alpestre produced a few seeds and hybrids that died as seedlings; however, hybridization with $4 x T$. alpestre produced vigorous hybrids in addition to increasing crossability, though using only $6 x T$. sarosiense as female (Quesenberry and Taylor, 1978; Maizonnier, 1972). In most cases less disharmony has been observed when the species with greater chromosome number is used as female (Hadley and Openshaw, 1980; Slesaravichyus and Dabkeyavichene, 1988; Kedrov-Zikhman et al., 1987); therefore, this should be a regular practice in crosses between species differing in chromosome number. In sugar beet, hybridization between $2 x B$. vulgaris and $4 x B$. patellaris resulted in triploid hybrids that had almost no roots and could be grown only after grafting onto sugar beet, but Loptien (1984b) obtained hybrids with viable roots by crossing a 
tetraploid sugar beet line with $B$. patellaris (4x). However, Dewey (1980) while reviewing the application of polyploidy as genetic bridge inferred that increased crossability and viability in hybrids are more prevalent when both species are diploid.

In these cases, besides the buffering capacity to accept a foreign genome, a proper balance in dosage of genes responsible for the development and differentiation of the embryo has probably been achieved under the changed genomic ratio of the two parents that support the development of the hybrid embryo. In others hybridization at the tetraploid level in an otherwise diploid species, besides providing the buffering capacity in the hybrid, results in a quasi-amphidiploid condition (each genome duplicated like amphidiploid) for the genomes involved, leading to a normal somatic cell cycle and normal gametic cell divisions through preferential intragenomic pairing. This helps overcome cytological instability caused at the diploid level by genomic incompatibility resulting in nonsynchronus movement and irregular segregation of chromosomes. In certain species, such as Datura stramonium, certain trisomics were found to enhance the development of hybrid embryos in interspecific crosses (Cole, 1956). This example suggests that development of a viable hybrid embryo can be promoted by an extra chromosome or gene(s).

A hybrid embryo can also break down at an early stage of development due to elimination of donor species chromosomes during embryogenesis. Prevention of this can result in normal development of hybrid embryo. In Hordeum vulgare x H. bulbosum crosses, Kasha and Sadasivaiah (1971) observed that elimination can be prevented by crossing autotetraploid $H$. bulbosum to diploid $H$. vulgare, whereas Thomas and Pickering (1983) in hybrids of $H$. vulgare $\times H$. bulbosum observed that an amphidiploid involving cultivar Vada had retained the bulbosum chromosome through a sexual cycle. They inferred that this genotype contains gene(s) that can prevent elimination of bulbosum chromosomes under the altered genetic ratio.

\section{B. Manipulating Endosperm Balance Number}

As discussed, in almost all angiosperms the survival of the embryo is dependent on the normal development of the endosperm. Hence, development of a normal endosperm is a prerequisite in the genetic improvement of crops by any technique involving sexual hybridization.

Endosperm dysfunctioning leading to its disintegration can be caused by several factors. Lin (1975) demonstrated that in Zea mays development of normal endosperm requires a $2: 1$ ratio of maternal and paternal chromo- 
somes. The $2: 1$ ratio is applicable to normal endosperm development and thereby seed development in most successful intraspecific and many interspecific crosses. However, there are many interspecific crosses where successful endosperm development is not determined by a $2: 1$ ratio of maternal and paternal chromosomes (Johnston et al., 1980). For example, when $4 x(2 n=4 x=48)$ Solanum acaule is crossed with cultivated $4 x(2 n=$ $4 x=48) S$. tubérosum, all seeds abort. Yet $S$. acaule crosses readily with several diploid species and even with dihaploid S. tuberosum $(2 n=2 x=$ 24 ), producing normal :seeds with $3 x$ embryos and normal endosperm (Irikura, 1968). This means that in $4 x S$. acaule $\mathrm{x} 4 x S$. tuberosum, though the maternal and paternal chromosome ratio in the endosperm is $4: 2(=2: 1)$, the endosperm aborts, causing incompatibility, while it develops normally in $4 x S$. acaule $\times 2 x S$. tuberosum even when the maternal and paternal chromosome ratio in the endosperm is $4: 1$.

To explain these intriguing results, Johns̄ton et al. (1980), advanced an endosperm balance number (EBN) hypothesis to define a single unifying factor controlling the development of endosperm in intraspecific interploidy and interspecific crosses. According to this hypothesis, each species has a genome-specific effective ploidy level (the EBN) which determines the development of endosperm in crosses with other species. For a cross to be successful, the hybrid endosperm must have a ratio of two EBN from the female parent and one EBN from the male. If the EBN ratio departs from this, the endosperm breaks down during development (Peloquin et al., 1982). The EBN can be ascertained by using one species against another as a standard. If the two species cross, they share the same EBN and produce 2:1 maternal : paternal ratio in the endosperm, thereby allowing its normal development to support the hybrid embryo. However, the EBN value can be different for two species with the same ploidy level. For example $2 x S$. chacoense crosses easily with $4 x S$. acaule to yield $3 x$ offspring. Therefore, $S$. acaule should have the same EBN as $S$. chacoense, and if we assign $2 \mathrm{EBN}$ for $2 x S$. chacoense then $4 x S$. acaule will also have $2 E B N$. On the other hand $2 x S$. chacoense does not cross with $4 x$ $S$. tuberosum, indicating that $S$. tuberosum does not have the same 2 EBN as $2 x S$. chacoense. Colchicine-induced $4 x$ (4 EBN) $S$. chacoense, however, crosses with $4 x S$. tuberosum to produce plump seeds. Therefore, $4 x S$. tuberosum should have an EBN of 4 . Based on this, according to the EBN hypothesis, hybrid ovules between $S$. acaule and $S$. tuberosum would have normal endosperm only when $4 x(2 \mathrm{EBN}) S$. acaule is crossed with either $2 x(2 \mathrm{EBN}) S$. tuberosum or when colchicine-induced $8 x$ (4 $\mathrm{EBN}) S$. acaule is crossed with $4 x(4 \mathrm{EBN}) S$. tuberosum. Consistency of this hypothesis has been demonstrated in many Solanum species (Johnston and Hanneman, 1980, 1982); and additional evidence is accumulating 
for several other crops such as Impatiens, (Arisumi, 1982), Avena (Nishiyama and Yabuno, 1979), and Trifolium (Parrott and Smith, 1986). This hypothesis can also explain differences in endosperm development between inter-EBN reciprocal crosses, because although the embryo in reciprocal crosses would be genetically the same, the endosperm would have different EBN ratios. For example, a 4 EBN x 2 EBN cross would have a maternal: paternal EBN ratio of $4: 1$ in the endosperm, while the reciprocal would have a $1: 1$ ratio (Nishiyama and Inomata, 1966; Nishiyama and Yabuno, 1979).

In this situation (excluding consideration of pollen-pistil and ovule barriers), two closely related species can be expected to cross if they share the same EBN. Two species with unlike EBN, such as EBN $=2$ and EBN $=4$ respectively, may be incompatible even at an identical ploidy level, as in many Solanum species (Johnston and Hanneman, 1982), diploid Avena (Nishiyama and Yabuno, 1979), Datura (Avery et al., 1959), and many Trifolium species within the same section (Parrott and Smith, 1986). However, such species can frequently be crossed by suitably altering the ploidy level and consequently matching the EBN number.

Overcoming the problem of endosperm breakdown through manipulating ploidy level and the EBN ratio in interspecific crosses can be exemplified by several successful intrasectional crosses between species of the section Petota (Johnston and Hanneman, 1982) and intrasectional hybrids produced in the genus Trifolium (Parrott and Smith, 1986). For example, crosses between $4 x T$. repens and $2 x T$. occidentale, and $8 x T$. repens and $4 x T$. occidentale fail due to a triploid block $(4: 1$ or $2: 2$ maternal : paternal EBN ratio in the endosperm, depending on the direction of cross) (Gibson and Beinhart, 1969). However, when $4 x T$. repens was crossed with autotetraploid $T$. occidentale, hybrids were obtained. Therefore, both the species have an EBN equivalent to their ploidy and when it matches at the tetraploid level hybridization is successful, resulting in plump seeds. Conversely, the cross between $4 x T$. repens and $2 x T$. nigrescens and between $8 x T$. repens and $4 x T$. nigrescens results in triploid and hexaploid hybrids, respectively (Trimble and Hovin, 1960; Brewbaker and Keim, 1953), while crosses between $4 x T$. repens and $4 x T$. nigrescens do not yield hybrid seeds (Evans, 1962a). These results contradict the triploid block hypothesis. However, they can be explained if $T$. nigrescens is assigned an EBN of twice its ploidy, so that $2 x T$. nigrescens would have $E B N=4$ and therefore would cross successfully with $4 x T$. repens $(4 \mathrm{EBN})$ or any other species with matching EBN rather than matching ploidy level (Parrott and Smith, 1986).

The establishment of EBNs in a group of species makes it possible to predict success in crosses and thus to manipulate polyploidy to produce 
the desired results. For example, with information on EBN number in Trifolium species, where $2 x T$. nigrescens has $\mathrm{EBN}=4$ and $2 x T$. occidentale has $\mathrm{EBN}=2$, hybridization between these two species would be expected to fail at the same ploidy level. It would therefore be necessary to raise the level of EBN in $T$. occidentale by autotetraploidy in order for hybridization between these two species to succeed. This was done in $T$. occidentale by Chou and Gibson (1968) and Gibson and Beinhart (1969), resulting in production of a hybrid with $T$. nigrescens. Similarly, for successful hybridization $4 x S$. acaule, with 2 EBN (having genes conferring resistance to virus $x$ ) and $4 x S$. tuberosum, with $4 \mathrm{EBN}$, the chromosome complement was doubled in $S$. acaule. Colchiploid $8 x$ (4 EBN) $S$. acaule crossed freely with tetraploid $S$. tuberosum $4 x$ (4 EBN) to yield hybrid progenies (Wangenheim, 1955). Subsequent backcrossing to $S$. tuberosum resulted in the transfer of resistance to virus $x$ into commercial cultivars of $S$. tuberosum. Besides these, a number of other examples exist in Trifolium and Solanum where interspecific hybridization failures, and successes after ploidy manipulations, have been explained on the basis of the EBN hypothesis (Taylor et al., 1959, 1963; Armstrong, 1968; Armstrong and Cleveland, 1970; Schwer and Cleveland, 1972b; Maizonnier, 1972; Rubtsov and Komkova, 1983; Parrott and Smith, 1986; Johnston and Hanneman, 1980, 1982).

However, it has been realized (Johnston et al., 1980; Johnston and Hanneman, 1980) that while matching EBNs may be necessary, it is not the only constraint for successful hybridization. Hybridization between species with the same EBN can also be prevented by prefertilization barriers (Evans, 1962b) and by incompatibility between the genomes of two species. Crosses between species with nonmatching EBNs may succeed, but only at a very low frequency. Nevertheless, it is to be hoped that, in crops where the EBN system apparently operates, breeders could identify potentially successful species combinations of crosses that can be achieved by the manipulation of ploidy level (and hence EBN) through the use of colchicine treatment.

Under the EBN hypothesis, the alteration in maternal: paternal EBN ratios resulting from change in numerical ploidy of one of the parents affects the normal development of the hybrid endosperm. However, recent evidence from experiments in Datura stramonium suggest that only 2 of its 12 chromosomes determine the EBN (Johnston and Hanneman, 1982). Similarly, Ehlenfeldt and Hanneman (1988) have presented evidence to support that in the cross $S$. commersonii x $S$. chacoense, the EBN system is controlled by three unlinked loci, which are homozygous within a species and have an additive effect. $S$. chacoense has twice the effect of $S$. commersonii, and a slight excess in maternal dose will produce 
a qualitative effect in relation to the number of viable seeds. Therefore, one can suggest that alteration in the dose of a single chromosome or gene can also result in normal development of endosperm.

\section{Using UNREDUCED $(2 n)$ Gametes}

Gametes with unreduced chromosome complements ( $2 n$ gametes) have been reported to occur naturally in variable frequencies in many plant groups (for details, see Veilleux, 1983). They have played a major role in the evolution of polyploid series in several plant species (Harlan and de Wet, 1975). Viable $2 n$ gametes from diploid parents also provide an alternative to chemical tetraploidization of diploid species that can overcome EBN and ploidy differences. Participation of $2 n$ gametes in fertilization has been observed in nature to produce occasional plump seeds with the unexpected ploidy levels-i.e., $4 x \times 2 x$ crosses produced $4 x$ progeny (Hanneman and Peloquin, 1967; den Nijs and Peloquin, 1977a,b; Johnston and Hanneman, 1980; Veronesi et al., 1986). For example an unreduced $(2 n)$ ovule of $S$. chacoense was fertilized with normal $2 x$ pollen of $S$. tuberosum, matching the EBN and permitting the development of endosperm because of the resultant 2:1 EBN ratio (Hanneman and Peloquin, 1968). Thus the 2:1 EBN requirement can serve as a selective screen for functional $2 n$ gametes. In Medicago, several authors have emphasized the importance of $2 n$ gametes in both evolution and breeding (Stanford et al., 1972; Veronesi et al., 1986).

In potato, Hanneman (1968) and Hanneman and Peloquin $(1967,1968)$ conducted an extensive study on crossability between $4 x$ cultivars of Solanum tuberosum and various $2 x$ Solanum species and species hybrids. They demonstrated that some species and their hybrids produce unreduced $2 n$ gametes and yield tetraploids in $4 x \times 2 x$ matings. Hence an attempt was made to transfer high tuber protein content into $S$. tuberosum from $S$. phureja exploiting $2 n$ pollen (Veilleux et al., 1981). In diploid crosses between $S$. tuberosum and wild diploid Solanum species, the capacity of $S$. tuberosum to form tubers under temperate conditions was transferred into hybrids. However, the breeding value of $2 n$ pollenproducing selections of $S$. phureja adapted to tuberization under long day conditions (Haynes, 1972) was shown to be equivalent or superior to that of these diploid hybrids (McHale and Lauer, 1981a,b; Veilleux and Lauer, 1981). In such $4 x \times 2 x$ crosses the possible two $S$. phureja alleles at each locus offered the opportunity for more interallelic interaction and hence potentially more heterotic responses (McHale and Lauer, 1981b).

Similarly, in alfalfa the presence of unreduced $(2 n)$ male and female gametes was revealed in interploid crosses of Medicago sativa and $M$. 
falcata, and $4 x \times 2 x$ hybrids were found to be more vigorous and fertile (Bingham, 1968; Bingham and Gillies, 1971). The importance of $2 n$ gametes has also been realized for unilateral genetic introgression in interploid crosses from wild diploids to the cultivated tetraploid alfalfa (Bingham, 1968). Veronesi et al. (1986) observed $2 n$ gametes in both the gynoecium and androecium of diploid crosses, which can result in maximizing hybrid vigor further at the tetraploid level through bisexual polyploidization.

Based on these principles, related Solanum species have generally been considered essential for providing new alleles by which maximum heterozygosity can be attained (Mendiburu et al., 1974). Sanford and Hanneman (1982) analyzed the yield potential of complex hybrids derived from $S$. andigena, $S$. phureja, and $S$. tuberosum germ plasm via unreduced $(2 n)$ gametes. They concluded that the $S$. phureja x haploid $S$. tuberosum hybrids have raised the possibility of a heterotic threshold above which no further increase in yield would be observed. However, breeding strategies that incorporate $2 n$ gametes into potato improvement have concentrated mainly on two goals: (1) production of seed-producing populations that can be used as cultivars; and (2) production of $4 x \times 2 x$ hybrids from which superior individuals can be selected for vegetative propagation. Both strategies have succeeded, although with some limitations. Further possibilities of exploitation of $2 n$ gametes in Solanum interspecific breeding are discussed under haploidy in Section IV,E,2 (for details; see Hermsen, 1983; Peloquin, 1983).

Diploidization of the egg has also helped in parthenogenetic development of a transformed egg in Nicotiana (Pandey, 1975, 1980). Pandey (1975) obtained a few viable seeds in certain combinations involving intercompatible species, such as $N$. forgetiana and $N$. alata, where mentor pollen had no effect and usually produced no seed. Many of the plants obtained from these seeds showed some characters of the mentor pollen parent. On observing similar results in several other Nicotiana species, Pandey (1980) extended a hypothesis to explain these results, in which induction of parthenogenetic diploidy, sustaining and influencing the selection of transformed eggs, played an integral part. He was also able to identify a major gene, closely linked with the S locus that induces parthenogenetic diploidy. If such genes and mechanism can be identified in other plant groups, the application of egg transformation in crop improvement will greatly increase.

\section{Providing Greater Versatility for Gene Transfer}

In the genus Ribes polyploidy has provided greater tolerance and versatility to transfer genes. For some difficult intersectional hybrid combina- 
tions, production of fertile amphidiploids by colchicine treatment of hybrid plants, followed by backcrossing with either diploid or autotetraploid forms of the Ribes cultigen, has rapidly eliminated the donor genome and reinstated the cultivated genotype (Keep, 1975; Nilsson, 1973). Backcrossing to the tetraploid produces $4 x$ plants that have three genomes from the recurrent parent and one from the donor. These tetraploids are more fertile than diploid derivatives and have provided more opportunity for the production of recombinants because of the doubled allelic dosage (Knight et al., 1974). Chromosome complements of cultivated Medicago sativa have been raised to $7 x$, and a complete autoploid series from $1 x$ to $8 x$ has been established. This has provided breeders with opportunities to move genes across the different ploidy levels through interploid bridge crosses (Bingham and Saunders, 1974). Wernsman and Matzinger (1966) proposed the use of octoploid $N$. tabacum as parent with diploid species. The pentaploid thus produced may then be backcrossed to $N$. tabacum and hybrid derivatives entered in a recurrent selection program for selection of commercial $N$. tabacum with desirable features from wild species. Similarly, Goldy and Lyrene (1984) in Vaccinium used octoploids to facilitate $4 x-6 x$ gene transfer. Savitsky (1975) succeeded in transferring nematode resistance from Beta procumbens $(2 n=18)$ to $B$. vulgaris $(2 x=18)$ by means of crosses between tetraploid $B$. vulgaris and diploid $B$. procumbens. The triploid $F_{1}$ hybrids were grafted to sugar beet and were grown for several years among diploid sugar beet pollinators. Backcrossing of triploid hybrids with diploid $B$. vulgaris resulted in four nematoderesistant plants carrying an additional chromosome of $B$. procumbens, which occasionally paired with $B$. vulgaris chromosomes to produce a trivalent and resulted in the production of two diploid plants with resistance to nematodes. In addition, successful interspecific crosses of several cereals with quantitative agronomic traits have been found superior at tetraploid level than at diploid level (Kuspira et al., 1985; Darmency et al., 1987).

\section{E. Production of Hybrid and Polyploid BRidges}

In the case of polyploid crop species, ploidy differences have been generally considered a barrier to genetic introgression from wild relatives due to either hybrid weakness or sterility. In breeding programs of such crop species, the primary method of genetic introgression has been to intercross directly parents of different ploidy levels and then $(a)$ use the hybrid progenies of intermediate ploidy level for further backcrossing; (b) use the progenies produced by these otherwise sterile hybrids with 
higher ploidy level in backcrossing; or (c)-double the chromosome complement in sterile hybrids to produce fertile amphidiploids and then use them in backcrossing with recipient parent. The second method to introgress exotic germ plasm has been to bridge the ploidy gap between the two parents by $(a)$ raising the chromosome level of the lower ploidy donor species to the ploidy level of the crop species with which it is to be crossed; (b) reducing the chromosome number of polyploid crop species to diploid and performing hybridization at the diploid level with their diploid wild relatives; or $(c)$ producing amphidiploids from hybrids of related wild species and using them in breeding programs either for direct hybridization with cultivated species or as a bridge for further crossing and backcrossing.

\section{Direct Hybridization}

Direct hybridization between species with different ploidy levels and use of the resultant hybrids in backcrossing to the recipient parent has been the commonest choice in attempting interspecific gene transfer. There are numerous examples of such gene transfers, particularly in allopolyploid crop species, such as wheat, tobacco, peanut, cotton, and mustard. Vardi and Zohary (1967), Gerechter-Amitai et al. (1971), and Vardi $(1970,1974)$ obtained genetic introgression from diploid to tetraploid wheat via a triploid hybrid. When triploid hybrids were pollinated with recipient parent pollen they did set occasional backcross seeds. Thus a reproductive barrier arising from ploidy differences could be effectively overcome by the occasional production of haploid, diploid, and unreduced balanced male and female gametes. Formation of trivalents in the $F_{1}$ and $\mathrm{F}_{2}$ progenies of such triploid hybrids indicates incorporation of alien substitution, due to homoeologous chromosome pairing, and the stabilization of a few progenies at the diploid and tetraploid levels, due to subsequent elimination of surplus chromosomes during meiotic segregation. Gill et al. (1986) incorporated resistance to herbicides (isoproturon) into Triticum durum from $T$. monococcum. Kerber and Dyck $(1969,1973)$ transferred stem rust resistance of $T$. monococcum $(2 n=14)$ to $T$. aestivum $(2 n=6 x=$ $42)$, by transferring it first to $T$. $\operatorname{durum}(2 n=4 x=28)$ through backcrossing the triploid hybrid to $T$. durum and then from $T$. durum to $T$. aestivum again by backcrossing the pentaploid hybrid to the appropriate recurrent parent. However, Alonso and Kimber (1984) and Gill and Raupp (1987) have obtained direct introgression from diploid T. tauschii and Aegilops squarrosa into hexaploid wheat using embryo rescue techniques for establishing hybrids and viable gametes for genetic introgression. Similarly, for 
transfer of genes from Agropyron species into wheat, direct hybridization between the two species always results in sterile $F_{1}$ hybrids. However, most of the hybrids gave progenies if treated with colchicine or backcrossed to wheat. Backcrossing to wheat varieties produced stable addition lines with either one genome (partial amphiploid) or one chromosome. Several of these lines have been used as sources of resistance to rust (Cauderon, 1979).

Chaplin and Mann (1961) crossed tetraploid Nicotiana tabacum with $N$. plumbaginifolia $(2 n=24)$ in order to transfer resistance to black shank disease (Phytophthora parasitica var. nicotianae). The hybrids were sterile but set seed readily when pollinated with N. tabacum. After one further backcross a resistant line was obtained in which resistance was incorporated in the $N$. tabacum chromosome complement, probably through homoeologous recombination. Apple $(1962,1967)$ and Goins and Apple (1971) were also able to transfer resistance to different races of black shank from $N$. plumbaginifolia using the same method. In peanut production of seeds and seedlings in otherwise sterile triploid hybrids between tetraploid A. hypogaea and diploid species of section Arachis (Singh and Moss, 1984b) has led to the initiation of backcrossing triploid hybrids to $A$. hypogaea to produce tetraploid derivatives rapidly. This has resulted in the establishment of some $A$. hypogaea-like tetraploid derivatives. Similarly, the partial fertility of a triploid $F_{1}$ hybrid between Brassica napus ( $2 n$ $=4 x=38$ ) and $B$. oleracea $(2 n=2 x=18$ ) (Ayotte et al., 1988) and in blueberry (Dweikat and Lyrene, 1988) led to the inference that use of triploids in backcrossing would make possible the introgression of agronomically desirable genes.

Another approach has been to select the progenies with the higher ploidy level obtained from $\mathrm{F}_{2}$ populations of these hybrids and to backcross them to the recipient parent. They have probably been produced as a result of fertilization between viable unreduced, haploid, diploid, or hyerdiploid gametes formed in these otherwise sterile hybrids, due to either the formation of restitution nuclei or balanced genomic segregation. These progenies theoretically will have achieved a greater degree of recombination between wild and cultivated species chromosomes than is obtainable in artificially induced amphidiploids. In the latter, recombination between donor and recipient species chromosomes is restricted because chromosomes in colchicine-induced hexaploids are duplicated in the somatic phase, and hence represent unaltered donor or recipient species chromosomes. These duplicated chromosomes preferentially pair with each other during the gametic cycle. On the other hand, chromosomes in progenies produced by selfing of triploids are the product of gametes that have undergone a meiotic division, where there is a greater opportunity for 
pairing between the donor and recipient species chromosomes. Some progenies have chromosome number near to that of the crop species and are important as they require fewer backcross cycles for the production of the desired ploidy levels. In peanut this approach has been effective, and several stable $A$. hypogaea-like tetraploid derivatives have been produced after backcrossing higher ploidy level progenies of triploids to A. hypogaea (Singh, 1986c).

Interploid hybrids produced by direct hybridization may have the same chromosome number and share common parents, but differ extensively in their behavior upon backcrossing and selfing. For example, when a hybrid contains two homologous and one nonhomologous genomes (AAB), most functional gametes would be diploid or nearly diploid. When it has three different genomes $(\mathrm{ABC})$, most functional gametes would be an unreduced triploid (Vardi and Zohary, 1967). Based on this principle, Dvorak (1977) concluded that a close inverse relationship exists between genetic introgression and polyploidization in natüre. However, the situation will be different when there is some homoeology between the genomes, and this would result in both homologous and homoeologus introgression as well as progenies with different ploidy levels.

Last and probably the commonest option in direct interspecific interploid hybridization is to double the chromosome number in sterile hybrids and to establish fertile amphidiploids. This may provide stability to the population and aid preservation of hybrid gene combination at higher ploidy level by dramatically enhancing the preferential pairing of homologous chromosomes (Evans and Davies, 1985). However, for specific gene transfer amphidiploids are then backcrossed to the recipient (recurrent) parent, usually the cultivated species. During backcrossing the chromosome number is returned to that of the cultivar and the favorable agronomic traits of the cultivated species are restored. Amphidiploidy has found its widest, and possibly the most important, application in creating fertile hybrids to facilitate gene transfer between species. The necessity of using amphidiploidy to overcome such hybrid sterility increases in direct proportion to the sterility of the $F_{1}$ hybrids. It offers the opportunity for moving genes between species where $F_{1}$ hybrids are completely sterile, and also provides buffering capacity for the acceptance of alien germ plasm in backcrossing. However, backcross progenies (e.g., $5 x$ ) of these relatively fertile amphidiploids may differ in their fertility, and some may be completely sterile to complicate and restrict the gene transfer (Singh, 1985). This happens as a result of an abnormal meiotic cycle resulting in gametic sterility or the abortion of the embryo. Therefore, selection of partially fertile progenies in backcross generations (which carry genetic factors supporting development of hybrid embryos) and use of backcross 
progenies as male parents (exploiting viable male gametes resulting from balanced genomic segregation) can overcome such problems.

Transfer of resistance to tobacco mosaic virus from Nicotiana glutinosa $(2 n=24)$ through a fertile alloploid between $N$. glutinos $a$ and $N$. tabacum called $N$. digluta was the first example of exploitation of amphidiploidy in gene transfer (Holmes, 1938). Valleau et al. (1960) transferred black shank resistance from $N$. longiflora $(2 n=24)$ to $N$. tabacum. The cross between these two species is easier if $N$. tabacum is used as the female parent. Hybrid seeds were treated with colchicine, and the resulting plants were backcrossed to $N$. tabacum. Johnston (1974) used colchicine to double the chromosome complement in a hybrid between Brassica campestris $(2 n=$ $20)$ and $B$. napus $(2 n=38)$ to produce an amphidiploid, and then backcrossed it to $B$. napus to obtain progenies with resistance to clubroot disease (Plasmodiophora brassicae). In wheat, Dyck and Kerber (1970) used a complex procedure involving induction of amphidiploidy to transfer two genes for leaf rust resistance from Aegilops squarrosa $(2 n=14)$ to $T$. aestivum. A synthetic tetraploid (AABB) extracted from the cultivar Canthatch (AABBDD) was crossed with $A$. squarrosa (DD), and colchicine was used to produce an amphidiploid (AABBDD), which was then backcrossed with T. aestivum (AABBDD). Cauderon's (1978) description of a stepwise transfer of a genome, a chromosome, and a gene from the perennial intermediate wheat grass (Agropyron intermedium) to annual wheat illustrates the advantages of introgression in stages. Through a series of backcrosses and selections, a stable octoploid $(2 n=56)$ with the full chromosome complement of wheat $(2 n=42)$ and 14 chromosomes of intermediate wheat grass was obtained. This amphidiploid had resistance to three wheat rusts. Backcrossing and selection resulted in a 44chromosome genotype that had the full wheat chromosome complement plus a pair of $A$. intermedium chromosomes and had regained all the agronomic traits of wheat. Finally, suppression of homoeologous pairing resulting in the transfer of the rust resistance of $A$. intermedium to an agronomically acceptable wheat background.

This approach has been used in peanut, since the first report in 1967 (Smartt and Gregory, 1967). Several diploid wild species belonging to section Arachis with an AA or BB genomic constitution have been crossed with the cultivated tetraploid species, $A$. hypogaea (AABB). The resultant triploid hybrids ( $\mathrm{AAwB}$ or $\mathrm{ABBw}$ ) have been treated with colchicine to double the chromosome number and produce fertile hexaploids (AABBAwAw or AABBBwBw) (Smartt and Gregory, 1967; Raman, 1976; Moss, 1980; Singh et al., 1980; Company et al., 1982; Singh, 1985). ${ }^{4}$ These hexaploids have then been backcrossed to $A$. hypogaea to reduce the

\footnotetext{
${ }^{4}$ In $\mathrm{Aw}$ and $\mathrm{Bw}$, "w" represents wild species genome.
} 
chromosome number to the tetraploid level so the agronomic traits of $A$. hypogaea could be restored. Multivalent associations observed in hexaploids and their backcross progenies suggest inter- and intragenomic homoeologous pairing between $A$. hypogaea and wild species chromosomes, resulting in the production of recombinants carrying both $A$. hypogaea and wild species traits. Selective elimination of wild species chromosomes, evident from preferential pairing observed between $A$. hypogaea chromosomes, and subsequent lagging of chromosomes in excess of $40(A$. hypogaea $2 n=40)$ during meiotic segregation at Anaphase I (AI) of several backcross progenies helped in production of stable $A$. hypogaea-like tetraploid derivatives (Singh, 1985). Spielman et al. (1979) and Company et al. (1982) recovered fertile $A$. hypogaea-like tetraploid progenies from similar hexaploid amphidiploids that were produced by Smartt and Gregory (1967), but were never backcrossed to A. hypogaea. Spielman et al. (1979) suggested that balanced viable gametes with predominantly $A$. hypogaea chromosomes can be produced from hexaploids by selective elimination of wild species chromosomes due to an irregular meiotic cycle.

In cotton, Meyer (1957) crossed $G$. armourianum $(2 n=26)$ with $G$. hirsutum $(2 n=52)$, produced an amphidiploid, and backcrossed it to $G$. hirsutum to transfer the smoothness character that provides resistance to the boll weevil, boll worm, and leaf worm. Since then several agronomically important characteristics have been transferred from wild diploid cotton to tetraploid cultivated cotton, often via artificially produced hexaploids. This includes resistance to several insects, plant smoothness, the nectariless trait, and cytoplasmic male sterility (Meyer, 1974). However, da Silva et al. (1975) in their cytological analysis observed that chromosome pairing in these hexaploids is essentially between duplicated homologues (intragenomic). Therefore, transfer of agronomic traits between cotton species with different genomes using this method appears to be difficult. Such predominant intragenomic pairing has also been observed in hexaploids of peanut (Singh, 1985).

In forage crops and to an extent in ornamentals the reduced fertility characteristic of interspecific gene transfer through sexual means is less critical than in crops primarily grown for seeds. In fact, even total sterility can be of advantage in some forage crops that can be propagated vegetatively. Therefore, significant progress has been made in improving forage crops and ornamentals (Terry-Lewandowski and Stimart, 1985) through interspecific genetic introgression via amphidiploidy. The superior quality of 14-chromosome annual rye grass was incorporated into 42-chromosome tall fescue through derived 56-chromosome amphidiploids. These amphidiploids were crossed as male parents to their $F_{1}$ counterparts, resulting in a 56-chromosome progeny; the chromosome complement in later generations dropped to $2 n=42$, the same as that in tall fescue 
(Webster and Buckner, 1971). After an extensive evaluation, a 42chromosome synthetic variety, Kenhy, was released, primarily on the basis of its improved quality (Buckner et al., 1977). However, in this case the exact mechanism of gene transfer was obscure. Recently, King et al. (1987) have observed a positive effect of ploidy on quality in Lolium x Festuca hybrids.

\section{Bridging the Ploidy Gap}

When the polyploids are to be used as genetic bridges, they simply serve as vehicles of gene transfer. If detailed information is available on the genomic constitution and relationships of species involved, then polyploids are more likely to be used for a predictable outcome in a breeding program in relation to hybrid fertility and genetic recombination, to combine the genomes of otherwise incompatible species and to transfer a specific gene or gene block(s) in increased dosage to provide greater interallelic recombination.

a. Autotetraploidy. In species complexes that have both diploid and tetraploid species, (e.g., alfalfa, orchard grass, crested wheat grass, potato, tobacco, peanut, and cotton), the cultivated species are predominantly tetraploid, and the wild relatives with desirable genes are diploid. Autotetraploids of wild species in these situations can be effective in two ways: (1) they can facilitate gene flow by bridging the ploidy gap; and (2) they may enhance viability of hybrids, as discussed earlier.

For example, gene flow between diploid and polyploid crested wheat grass is virtually nil because of complete hybrid sterility (Knowles, 1955). The small amount of genetic exchange that occurs is unidirectional, from diploid to polyploid (Dewey, 1971). However, doubling of the chromosome complement of diploid crested wheat grass overcomes crossing barriers, resulting in fertile interploid hybrids, and also facilitates bidirectional gene flow (Dewey and Pendse, 1986; Dewey, 1977).

In certain allopolyploid crops, such as cotton, tobacco, tomato, peanut, and coffee, this approach has been applied successfully with defined objectives. Knight $(1953,1954)$ succeeded in transferring two genes for blackarm resistance from Gossypium arboreum (AA) to G. barbadense (AADD) by first doubling the chromosome number in the diploid species and then crossing the autotetrapoid with $G$. barbadense. The hybrids (AAAD) showed very low fertility, but it was possible to obtain a sufficient number of backcross progenies by growing more $F_{1}$ plants and pollinating all the 
flowers each day with $G$. barbadense pollen. In coffee, an interspecific hybrid between $C$. arabica and induced tetraploid $C$. canephora, the arabusta hybrid, was produced with the objective of improving the liquor quality of robusta; backcrossing of this to $C$. arabica resulted in rapid restoration of fertility (Owuor and van der Vossen, 1981; Owuor, 1985).

In peanut, rust resistance from $A$. batizocoi $(\mathrm{BB})$ has been successfully transferred to $A$. hypogaea (AABB) using an autotetraploid of $A$. batizoco $i$ (BBBB). The hybrids were backcrossed to $A$. hypogaea, and rust-resistant segregants were obtained (Singh, 1986a). Using the same principle, several other A-genome species autotetraploids of section Arachis have been crossed to A. hypogaea to bring about both homologous (AA) and homoeologous $(\mathrm{AB})$ chromosome pairing and achieve genetic alteration in both A and B genomes of $A$. hypogaea (Singh, 1986a).

In tobacco (Chaplin and Mann, 1961) and tomato (Rick et al., 1986), sesquidiploids have been used to overcome problems in the production and fertility of hybrids. Sesquidiploids are hybrids that are diploid for the chromosomes of one species (usually the cultivated species) and haploid for the other. They can be produced by doubling the chromosome number of the cultivated species, for example $N$. tabacum, and crossing the tetraploid with the alien species. Alternatively, if hybrid plants can be obtained from crosses between the diploids, then the chromosome complement of the $F_{1}$ plants can be doubled, and backcrosses are made to the cultivated species to obtain sesquidiploids, for example, in lavender (Rabotyagov, 1982) and tomato (Rick et al., 1986). Sesquidiploids are usually moderately fertile, so they may be either selfed or backcrossed to the cultivated species. After initial meiotic recombination as a result of homoeology, preferential pairing between the cultivated species chromosomes can lead to an orderly segregation of chromosomes to form balanced gametes with the whole complement of the cultivated species. Extra chromosomes of wild species can be transmitted to produce viable alien chromosomes addition lines, which can be used in the transfer of desirable genes from wild relatives to the cultivated species.

Autoploidy has been of value in other ways, which have not been fully elucidated. For example, Nicotiana longiflora, a source of resistance to wildfire disease, produces hybrids with $N$. tabacum that die at an early stage. Clayton (1947) crossed tetraploids of the two species, and again most hybrids died except for a few weak seedings which flowered but were sterile. After 18 months three plants produced galls at the base while their apices died. New vigorous shoots developed from these galls. One resistant plant was successfully backcrossed to $N$. tabacum, and after several generations of selection a resistant stock was obtained. It was also found to be resistant to backfire. 
b. Haploidy. Reduction of the ploidy level of the cultivated species to that of the wild species is usually more difficult than the reverse process. However, recent developments in techniques for in vitro androgenesis and gynogenesis (Maheshwari et al., 1982; San and Gelebart, 1986), along with discoveries such as chromosome elimination in vivo, pseudogamy or parthenogenetic development of unfertilized ovules under the influence of foreign pollen on interspecific hybridization, and semigamy, where reduced male and female gametes participate in embryogenesis, may increase the frequency of haploid production in crop species (Hermsen and Ramanna, 1981; Han and Hangyuan, 1987). Working at the diploid level has several advantages, such as simpler genetic ratios, absence of any dosage effect, and the rapid attainment of homozygosity.

Production of dihaploids through pseudogamy and in vitro anther culture in the tetraploid potato has become routine and is being applied in most breeding research programs (Hermsen, 1983). Hougas and Peloquin (1962) produced dihaploid lines of $S$. tuberosum $(2 n=24)$ and successfully crossed them with 24 diploid species. Increased chiasma frequencies, observed by Singh et al. (1989) in diploid hybrids between several diploid species of section Petota and dihaploid $S$. tuberosum $(2 n=2 x=24)$, suggest greater recombination between $S$. tuberosum and the related diploid species at diploid level. Broksh (1982) observed that seed fertility of dihaploids was best increased by hybridization with diploid species. These factors should help in rapid incorporation of genetic diversity from wild diploid species and establishment of hybrids. However, no tuber yield benefit was observed in the crosses involving diploid $S$. phureja, S. stenotomum, and $S$. chacoense and dihaploids from $S$. tuberosum subspecies, andigena, and neotuberosum, probably because diallelism is the maximum level of heterozygosity possible at the diploid level (Bingham, 1980). Nevertheless, this has indicated the possibility of simple gene transfer. As a result, potato breeding has gone several steps further, and a number of modified approaches have been proposed to overcome breeding limitations (Wenzel et al., 1979; Peloquin, 1983). The overall strategy encompasses three components: (1) wild species providing genetic diversity; (2) haploids of $S$. tuberosum providing a means to capture the genetic diversity; and (3) unreduced ( $2 n$ ) gametes as efficient carrier of genetic diversity.

Peloquin (1983) presented four breeding schemes, which involve unilateral or bilateral sexual polyploidization to obtain $4 x$ progeny from $4 x \mathrm{x}$ $2 x$ first division restitution (FDR) crosses and $2 x$ FDR $x 2 x$ FDR crosses. Restitution nuclei and unreduced gametes are formed in parents, for example by the parallel spindle formation (Mok and Peloquin, 1975). For this approach haploids of cultivars $(2 n=2 x=24)$ are crossed with diploid wild 
species $(2 n=24)$ having desirable traits and the capacity to form unreduced $(2 n)$ gametes. Superior recombinants are then selected with the capacity to form $2 n$ gametes by FDR. Such hybrids have been made by crossing a $S$. tuberosum dihaploid $(2 n=2 x=24)$ to $S$. phureja $(2 n=2 x=$ $24)$, to $S$. chacoense $(2 n=2 x=24)$ (Hanneman and Peloquin, 1969; Leue and Peloquin, 1981) and recently to many more wild species (Hermundstad and Peloquin, 1985). Selected $2 x$ hybrids are then crossed either to $4 x$ cultivars with good adaptation ( $4 x$ cultivar $\mathrm{x} 2 x$ hybrid, FDR pollen) or another $2 x$ hybrid involving $2 x$ cultivated species ( $2 x$ hybrid, $2 n$ egg $\mathrm{x} 2 x$ hybrid, $2 n$ pollen) (for details see Peloquin, 1983). In such a $4 x \times 2 x$ (FDR) and $2 x$ (FDR) $\times 2 x$ (FDR) cross, the agronomic traits of cultivated species are combined with desirable features of wild species. Following this, $S$. phureja and $S$. chacoense have provided a reservoir of genetic diversity to improve many agronomic traits of the commercial potato and also genes for disease and insect resistance. Alfalfa is another autotetraploid where haploidy and $2 n$ gametes can play a similar role in interspecific genetic introgression and in maximizing heterozygosity in this crop (Bingham, 1968, 1983; Stanford et al., 1972; Barnes et al., 1977; Bingham and McCoy, 1979).

The effectiveness of these schemes in potato has been further increased with the discovery of a new meiotic variant, sy3. This gene causes the formation of univalents only, thereby restricting crossing over (recombination). Ordinarily this would have resulted in complete male sterility. However, when it is combined with another mutant parallel spindle at the second meiotic division $(p s)$, fertile unreduced $(2 n)$ gametes are produced containing all parental genotypic variation due to failure of reduction division. Thus an exceptional opportunity has arisen, wherein $100 \%$ heterozygosity can be incorporated into hybrids at least from the male side (Okwaugwu and Peloquin, 1981). Efforts are under way to identify a similar mechanism for production of unreduced gametes on the female side as well, which would further increase the efficiency of the scheme, making it possible to combine $100 \%$ genetic information of two parents together into a fertile hybrid. Otherwise, this is possible only through parasexual somatic hybridization.

c. Amphidiploidy. Amphidiploidy has found its widest and possibly most important application in effecting gene transfer between species by (1) restoring fertility in sterile $F_{1}$ hybrids, as discussed earlier, and (2) providing bridges to bring about controlled introgression through direct hybridization between a cultivated species and a wild species synthetic amphidiploid with the same (or very similar) genomes, in order to maintain some control over chromosome pairing and still obtain the desired amount 
of recombination between genomes. Also, amphidiploidy makes it possible to establish a bridge between a crop species and a directly incompatible species by crossing the latter with a mutually compatible third species and doubling the chromosome number in the resultant $F_{1}$ hybrid. These approaches have been more commonly used in allopolyploid than in autopolyploid crop species.

The use of amphidiploidy in controlled introgression may range from the transfer of a whole genome to that of a single gene. The transfer of leaf rust (Puccinia triticina) resistance from (Aegilops umbellulata to Triticum aestivum via an amphidiploid of $T$. dicoccoides $\mathrm{x} A$. umbellulata by Sears (1956) is a classical example of an integrated use of amphidiploidy, backcrossing, irradiation, and selection in an interspecific breeding program for the incorporation of a single chromosomal segment. The ability to manipulate pairing between homologous versus homoeologous chromosomes in bread wheat has stimulated further interest in controlled genetic introgression, of which amphidiploidy is just a part. However, such a control mechanism has been exhaustively investigated and used only in wheat, and in oats for the transfer of powdery mildew resistance (Thomas et al., $1980 \mathrm{~b}$ ), though there are indications that similar systems may exist in other crops, for example in Gossypium (Kimber, 1961). An intensive cytogenetic effort is required if breeders wish to exploit these possibilities in genetic introgression.

The mechanism of interspecific gene transfer using amphidiploids as bridges in most of the crop species may not be as elegant as in wheat, but the practical use of amphidiploid bridges in crops such as tobacco, potato, cotton, and peanut has been as effective as in wheat and probably in many cases even more so. One such crop is cotton, where the triple hybrid involving the induced amphidiploids of Gossypium arboreum $\times$ G. thurberi crossed with $G$. hirsutum has been widely used in cotton breeding for improving fiber strength of upland cotton (Culp and Harrell, 1973). Recently, Mirakhmedov et al. (1985) using an allotetraploid of $G$. thurberi x G. ramondii has been able to transfer wilt resistance into both $G$. hirsutum and $G$. barbadense. Similarly, in tobacco the amphidiploid between $N$. sylvestris $\times 1$. otophora, when hybridized with $N$. tabacum, has been utilized for commercial exploitation (Wernsman and Matzinger, 1966). In peanut, Smartt et al. (1978) speculated about difficulties in genetic introgression using synthetic amphidiploids of diploid species from section Arachis. However, subsequent genome analysis (Singh and Moss, 1982, 1984a) has suggested homoeology between the two genomes (A and B) of section Arachis and, therefore, the possible potential of this option. Chromosome pairing in $A$. hypogaea x amphidiploid hybrids confirmed both $\mathrm{AB}$ and $\mathrm{A}$ (wild)-A (cultivated) pairing (Gardner and Stalker, 1983; 
Singh, 1986b), indicating practical utility of $\mathrm{AAA}^{\prime} \mathrm{A}^{\prime}$ and AABB amphidiploids in genetic introgression from wild species to $A$. hypogaea (Stalker and Moss, 1987). Hybridization between A. hypogaea and the synthetic amphidiploids of section Arachis species, followed by subsequent backcrossing to recipient species, has effected the transfer of genes conferring resistance to late leaf spot, early leaf spot, and rust from the diploid wild species of section Arachis into cultivated A. hypogaea (Gardner and Stalker, 1983; Singh 1986b). Thus, amphidiploidy has facilitated the incorporation of a trait, or a combination of desired traits, such as rust and late leaf spot resistance, through intragenomic and intergenomic interspecific chromosome pairing (Singh, 1986c).

The other use of amphidiploidy is in establishing a bridge that can provide access to an incompatible species to produce fertile hybrids. A number of Nicotiana species either cannot be crossed with $N$. tabacum or, if they can, the hybrids are sterile. A bridging cross may be necessary in such cases. Nicotiana repanda $(2 n=48)$ has resistance to many tobacco diseases, including the root knot nematode (Meloidogyne javanica), but it is generally impossible to cross it with N. tabacum. Burk (1967) and Schweppenhauser (1968) used $N$. sylvestris as a bridge species in an attempt to transfer nematode resistance from $N$. repanda. Burk (1967) crossed $N$. repanda with $N$. sylvestris and backcrossed twice to $N$. sylvestris. Eight resistant backcross progenies were later crossed to N. tabacum, of which only three produced seeds. Schweppenhauser (1968) then crossed the amphidiploid $N$. repanda x $N$. sylvestris with $N$. longiflora. The $F_{1}$ plants were selfed and resistant $F_{2}$ progenies were then crossed and backcrossed twice to $N$. tabacum. This yielded $N$. tabacum plants with an added alien chromosome. Stavely et al. (1973) crossed tetraploid N. tabacum with the amphidiploid $N$. repanda $\mathrm{x} N$. sylvestris in an attempt to - transfer resistance to Alternaria alternata, Cercospora nicotianae, and Meloidogyne javanica. The sterile $\mathrm{F}_{1}$ hybrids were treated with colchicine to double the chromosome number and restore fertility and were then backcrossed to $N$. tabacum twice, successfully transferring the resistance to Meloidogyne javanica and Cercospora nicotianae.

Similarly, in the case of Solanum, there are several species from the Mexican series with desirable traits, but they will not cross directly with $S$. tuberosum. Dionne (1963) found that $S$. acaule, a species compatible with $S$. tuberosum, can cross with several of these species, which established that $S$. acaule can be used as a bridge for introgression of gene(s) from these species into $S$. tuberosum. Sterile triploid hybrids were obtained from crosses between $S$. acaule and these species, and hexaploids were produced by doubling the chromosomes. A hexaploid, $S$. acaule $\mathrm{x} S$. pinnatisectum, was successfully crossed with both diploid and tetraploid 
species of series Tuberosa, confirming that $S$. acaule can be used as a bridge. The success of this scheme led Hermsen and Ramanna (1973) to attempt to transfer disease resistance from an incompatible wild diploid species, Solanum bulbocastanum $(2 n=2 x=24)$, to the cultivated tetraploid, $S$. tuberosum, using two additional wild species, $S$. acaule and $S$. phureja. S. acaule was crossed with $S$. bulbocastanum to produce a triploid $F_{1}$ hybrid. The chromosome number was doubled in this hybrid to produce a fertile hexaploid, which was then backcrossed to $S$. phureja to produce tetraploid hybrids. These tetraploid hybrids were crossed to potato cultivars to give quadruple (consisting of four species genomes) hybrids. When hybridization of Lycopersicon esculentum x Solanum lycopersicoides sesquidiploid to $L$. esculentum failed, Rick et al. (1988) used $L$. pennellii as bridge species. Selected diploid and trisomic progenies of $\mathbf{B C}_{1}$ with $L$. esculentum characters were further backcrossed to L. esculentum.

\section{G. Transfer of Chromosomes, Genes, or Gene Blocks}

As indicated earlier, interspecific gene transfer requires the transfer of a chromosome segment from the donor species into a chromosome of the recipient, without affecting the genomic balance of the latter. Therefore, techniques that can transfer a single chromosome instead of the whole genome, and can substitute an alien chromosome segment without adversely affecting the genome of the recipient species (cultivar), would be more attractive and effective than the methods discussed above. Polyploidy, particularly aneuploidy, has been an integral part of such manipulations, for example, in wheat (Kimber and Sears, 1980).

O'Mara (1940) was able to add individual rye chromosomes that had different phenotypic effects onto the wheat genome by backcrossing the amphidiploid between the two species to wheat and selecting addition lines from the progeny of the backcrosses (Fig. 1). However, in such an approach the introduction of alien chromosomes may sometimes inhibit and complicate genetic introgression as a result of the adverse effect of the introduced chromosome on the gametic cycle. Such attempts would thus be unpredictable until a complete aneuploid series of a crop species was available, with information on relationships and the effect of alien chromosomes on the regularity of chromosome behavior and fertility in the recipient species. Nevertheless, chromosome addition lines are the starting material for chromosome substitution to induce transfer of alien genes.

Once an addition line has been produced, substitution of an additional pair of alien chromosomes into a recipient parent is achieved by crossing a monosomic plant of the recipient parent for a particular chromosome to 


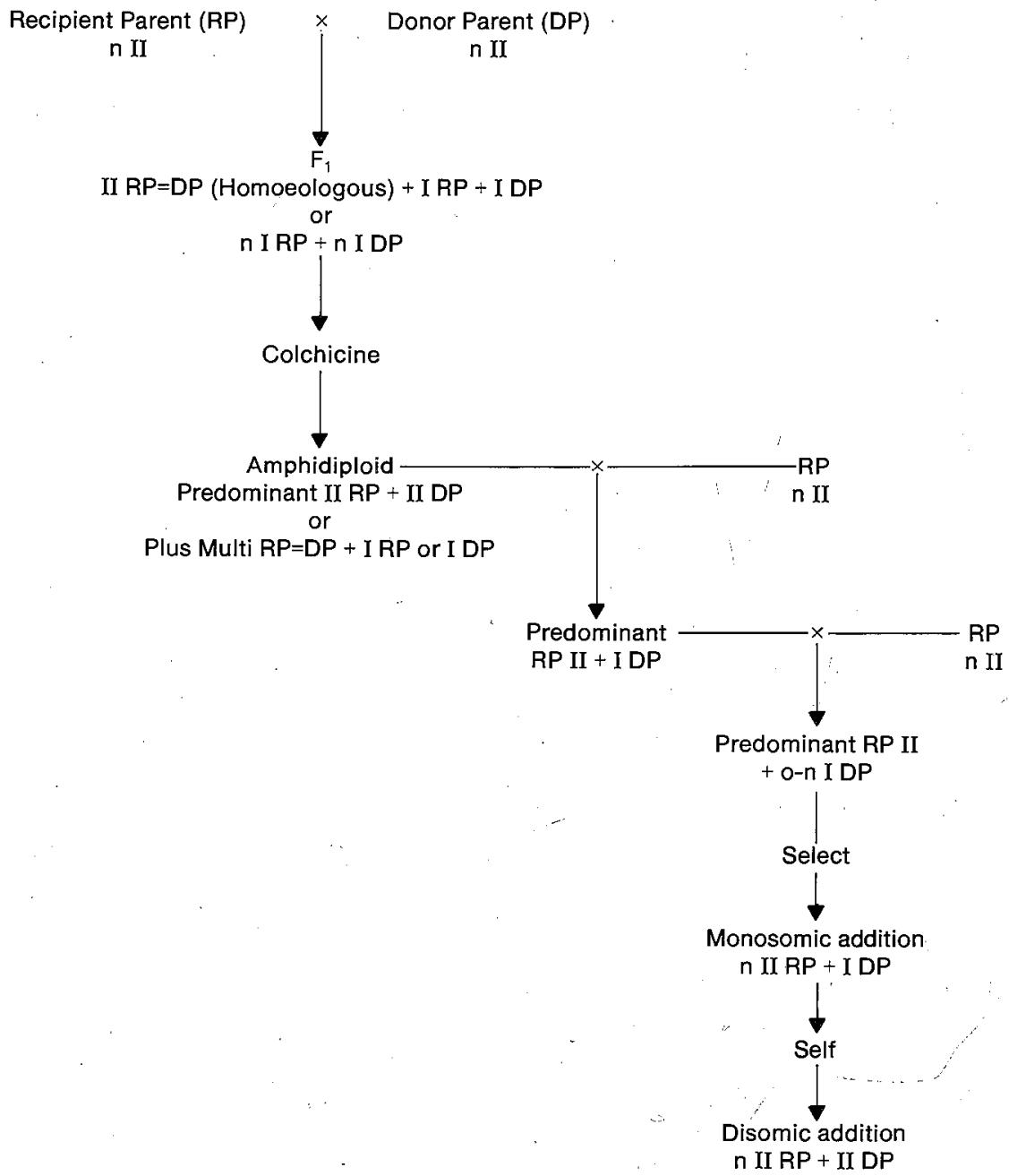

Fig. 1. Production of addition line.

the disomic alien addition line. From the progeny, plants are selected that are monosomic for the relevant chromosome of the recipient species and the alien chromosome. Alternatively, if the above dimonosomic genotype (simultaneously monosomic for alien and a recipient chromosome) is crossed with the same disomic addition line, it will produce some progeny with $n$ bivalents plus one univalent. These progenies will have two different genotypic constitutions, one of which will have $n-1$ bivalents and a 
Monosomic Recipient Parent (RP) $\mathrm{n}-1 \mathrm{II}+1 \mathrm{I}$

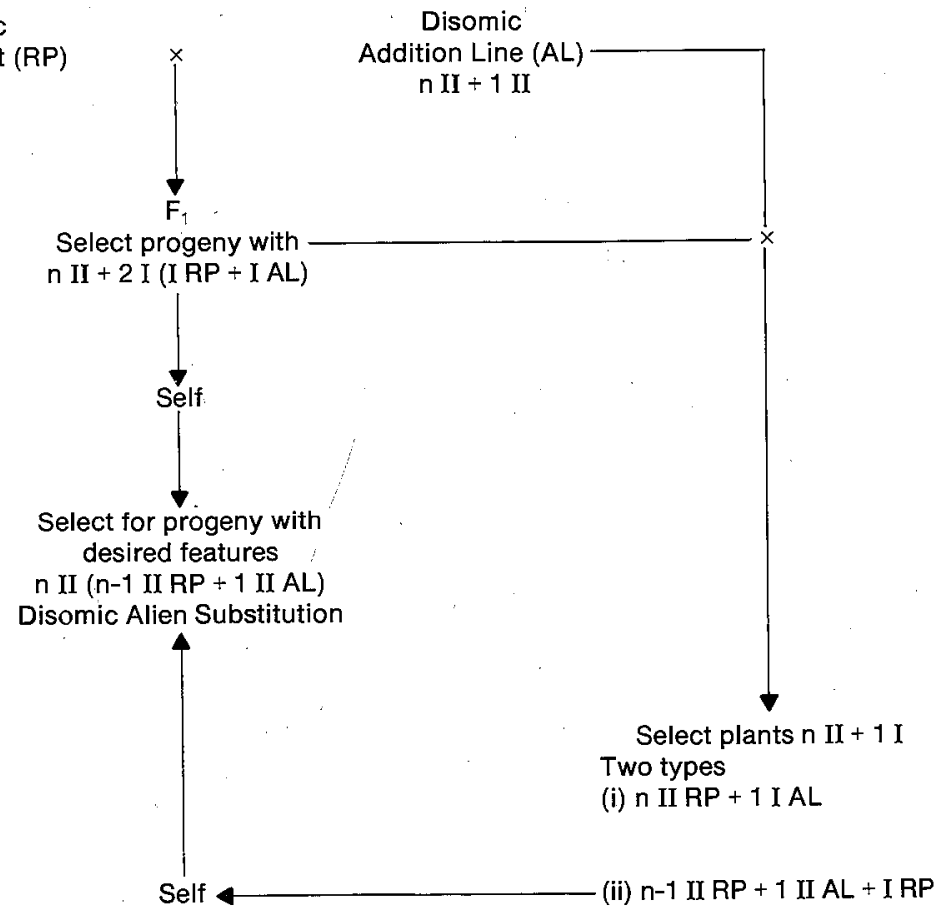

Frg. 2. Production of substitution line.

monosome of the recipient species, and a bivalent of the alien chromosomes. Selfing of such a plant will yield disomic substitution lines (Fig. 2).

If substitution lines are to be successful, the prerequisites are (1) that the alien chromosome must compensate.for the loss of the chromosome of the recipient species; (2) that it must become integrated in the genotype without disturbing meiotic stability and fertility; and (3) that it must confer some agronomic benefit to the crop species. The chromosomes of Secale, Agropyron, and Triticum (Aegilops) are homoeologous with corresponding wheat chromosomes; each is therefore able to compensate in the pollen for the absence of a particular wheat chromosome. Some wheat cultivars bred in Germany and eastern Europe have been shown to be substitution lines of chromosome 1R of rye for 1B of wheat (Zeller, 1973; Mettin et al., 1973). Triticale was used in breeding of these wheat cultivars.

Addition or substitution lines are not always beneficial, due to either instability that may be caused by the introduction of a complete alien chromosome, or linked undesirable traits also being transferred. The next step in such cases is the transfer of a segment of the donor species chroma- 
tin to a chromosome of the recipient species. Ideally this segment should be as small as possible to avoid the problem associated with addition and substitution lines. When there is sufficient genetic homology between the species to allow some degree of pairing between chromosomes and genetic exchange, as discussed earlier, a segment of chromosome from one species can be transferred to another through meiotic recombination. However, for a situation where this is restricted because of either nonhomology or a genetic mechanism restricting pairing, several procedures for introducing segments only of the alien chromosomes have been established.

Sears (1956) was the first to use irradiation to induce translocation to transfer resistance to brown rust from Aegilops umbellulata to bread wheat. Driscoll and Jensen (1963) were also successful in inducing translocation by irradiating dry seeds of disomic alien addition lines. The usefulness of such introgression depends upon the ability of the genotype to tolerate deficiencies and duplications which may be created and compensated for by another homoeologous chromosome. Aung (1975) identified a number of the translocations involving transfer of mildew resistance from Avena barbata $(2 n=28)$ to A. sativa $(2 n=42)$ after irradiating seeds of the disomic addition line. Evidence was also presented (Thomas, 1981) that such a translocation can also depress yield in certain genetic backgrounds. An assessment of such transfers in a wide range of genetic backgrounds is an essential prerequisite for breeding programs.

Knott (1968) and Dvorak and Knott (1977) found that transfer of Agropyron genes into wheat by induced translocations involved an exchange between homoeologous chromosomes, and that deletion of wheat chromatin was compensated for by the segments of the homoeologous Agropyron chromosome, where in Avena gene transfer, the loss of a segment of the recipient species was tolerated (Aung and Thomas, 1978).

The failure of alien chromosomes to pair is not always associated with nonhomology; it may be due to the genotype of the plant with respect to genes that control chromosome pairing. In wheat, Riley and Chapman (1958) and Sears and Okamoto (1958) discovered the $\mathrm{Ph}$ gene on the long arm of chromosome 5B, which restricts pairing to homologous chromosomes and prevents homoeolgous pairing. Such a genetic system can also restrict pairing with alien homoeolgous chromosomes in a hybrid or addition line. Nevertheless, this genetic control can be manipulated to allow alien chromosomes to pair with corresponding homoeolgous chromosomes of wheat. Riley et al. (1968) used Aegilops speltoides, which suppresses the Ph gene activity, while Sears (1973) used an aneuploid lines nullisomic for the $5 \mathrm{~B}$ chromosome to promote pairing between wheat and homoeolgous alien chromosomes. Darvey (1984) proposed construction of 
an alien gene bank by employing the $\mathrm{Ph}$ mutant gene and alleles similar to $\mathrm{Ph}$ in polyploid Aegilops species in a direct hybridization breeding program with alien species. In Avena hybrids, the effect of $A$. longiglumis on chromosome pairing, reported by Thomas and Al-Ansari (1980), has been successfully exploited for the transfer of mildew resistance from A. barbata to cultivated oats (Thomas et al., 1980b). The crossing scheme involved hybridization between an amphidiploid of $A$. sativa $\times$ A. longiglumis $(2 n=56)$ and a ditelosomic addition line with the short arm of $A$. barbata $(2 n=42+1)$. The $\mathrm{F}_{1}$ hybrid $(2 n=49+1$ telocentric $)$ was resistant, and when it was backcrossed twice to $A$. sativa, an individual progeny (Av 1860) in which the telocentric chromosome was absent was identified with resistance to mildew. This suggested that there had been segmental exchange between $A$. barbata and $A$. sativa chromosomes. In plants monosomic for alien and recipient species chromosomes, misdivision of univalents and union of resulting telocentrics can produce a chromosome including arms of both univalents (Sears, 1972). Sears was successful in producing a wheat-rye translocation using this method. In a situation where the alien chromosome fails to pair even after induced homoeolgous pairing, this method can be a very effective alternative.

When genetically induced chromosome substitution, promoting homoeolgous pairing, is used, meiotic stability must be obtained by reintroduction of genetic control, restricting pairing to homologous chromosomes. Similarly, if this genetic system to stabilize the meiotic behavior can be transferred into synthetic polyploids, it could be suitably exploited to facilitate production and fixation of novel recombinants and the synthesis of alloploids.

\section{CONCLUSIONS}

There is a growing interest in crop improvement, especially by exploiting exotic germ plasm. The most important characters of interest are resistances that are not available in crop species to diseases and pests that are major constraints in crop production. The discovery of the use of colchicine for chromosome doubling in the 1940s and production of haploid plants from anther culture in the 1960s raised great hopes for the use of ploidy manipulations in interspecific gene transfer. Problems are encountered in interspecific gene transfer, but polyploidy has played a role (1) in overcoming cross-incompatibility, by regulating ploidy level in gametes, endosperm, or embryo; (2) in providing buffering capacity for the acceptance of a foreign genome; (3) in restoring fertility in sterile species hy- 
brids; (4) in serving as a genetic bridge to transfer genes between species; and (5) in regulating chromosome pairing to effect incorporation of specific segments.

Polyploidy was used initially out of curiosity because of increased vigor and for restoring fertility in sterile hybrids. However, research in the 1980s has produced explanations for and has further elaborated the role polyploidy can play in regulating hybrid fertility and genetic introgression in light of genomic relationships between the species. The formulation of principles such as the EBN hypothesis and the discovery of the genetic control of chromosome pairing encourage optimism, but there is still a challenge to cytogeneticists and breeders to use these techniques in a wider range of plant groups and to develop new techniques. In a particular cross, an understanding of the reasons for the failure of the cross, knowledge of the factors controlling fertility of the hybrid, and the ability to promote the desired meiotic recombination are essential prerequisites. The principles discussed in this article have been identified, and standard procedures for interspecific gene tránsfer have been devised in only a few crop species, such as wheat, potato, and oats, where there has been a large research effort for which genome structure and cytogenetic affinities between related species are very well understood and documented. Such studies are another prerequisite for the exploitation of ploidy manipulations in interspecific gene transfer.

Induced autoploids that have fallen short of expectations for direct usage in agriculture may yet play an important role in enhancing crossability and in facilitating gene flow between cytotypes, biotypes, and species complexes. Amphidiploidy offers the opportunity for genetic introgression between species whose $F_{1}$ hybrids are completely sterile. As a bridge, also, amphidiploidy has been used most frequently in transferring both simple and complex heritable traits between species. Recent achievements in the production of haploids through in vitro and in vivo methods have made breeding at the diploid level possible for polyploid species. In potato, haploids have provided a method for capturing genetic diversity, and unreduced gametes, an effective means to transmit all the allelic variation necessary to produce or maintain maximum heterozygosity. These trends indicate that the importance of induced polyploidy will not necessarily decrease as more sophisticated methods of gene transfer or genetic transformation develop.

Once successful crosses and backcrosses have been produced, introduction of only desirable segments into a balanced acceptable genetic background of a cultivated species is still a major concern. Difficulties arising from duplication, deficiencies, and linkage between desirable and undesirable characters still provide a challenge to cytogeneticists. Usually 
they can be overcome by repeated backcrossing, raising of large hybrid populations, and exploitation of homoeolgous pairing. The development of special cytogentic procedures of chromosome engineering, as described for wheat, may be necessary for other crops as well. It is well documented that the genetic background can influence expression of a desirable trait, and also that the effect of introduced deleterious gene(s) may be important. Therefore, attempts to produce a wide range of cross combinations may be necessary.

Novel techniques for transformation at the cellular and/or molecular levels provide enormous opportunities for extending the range of gene introductions. They are generating much interest and undoubtedly present exciting prospects for the future of plant breeding. However, these have been applied to relatively few crops, and there are difficulties in many cases, such as the production of plants from transformed cells. Therefore, existing cytogenetic methods of genetic manipulation will continue to be the principal means of effecting interspecific gene transfer for the foreseeable future. Much work is still required to perfect the techniques of chromosome engineering in major crop species, which could reduce the size of the alien chromosome segment that can be transferred. If wheat has provided such scope for improvement using these techniques of chromosome engineering, why not other crop species as well?

\section{ACKNOWLEDGMENTS}

The authors would like to acknowledge with thanks the technical and secretarial assistance provided by Mr. T. P. Shyamal Rau and Mrs. Sashikala Kishore respectively.

\section{REFERENCES}

Alonso, L. C., and Kimber, G. 1984. Z. Pflanzenzuecht. 92, 185-189.

Apple, J. L. 1962. Phytopathology 52, 1. Abstr.

Apple, J. L. 1967. Tob. Sci. 11, 79-83.

Arisumi, T. 1982. J. Hered. 73, 57-65.

Armstrong, K. C. 1968. Ph.D. Thesis, Pennsylvania State Univ., Univ. Park.

Armstrong, K. C., and Cleveland, R. W. 1970. Crop Sci. 10, 354-357.

Ashley, T. 1972. Planta 108, 303-317.

Aung, T. 1975. M.S. Thesis, Univ. of Wales.

Aung, T., and Thomas, H. 1978. Euphytica 27, 731-739.

Avery, A. G., Satina, S., and Rietsema, J. 1959. "Blakeslee: The genus Datura." Ronald

Press, New York.

Ayotte, R., Harney, P. M., and Machado, V. S. 1988. Euphytica 37, 189-197.

Barnes, D. K., Bingham, E. T., Murphy, R. P., Hunt, O. J., Beard, D. F., Skrdla, W. H., and Teuber, L. R. 1977. USDA-ARS Tech. Bull. No. 1571. 
Bingham, E. T. 1968. Crop Sci. 8, 760-762.

Bingham, E. T. 1980. In "Polyploidy: Biological Relevance" (W. H. Lewis, ed.), pp. 471-489. Plenum, New York.

Bingham, E. T. 1983. In "Better Crops for Food" (J. Nugent and M. O'Conner, eds.), Ciba Found. Symp., Vol. 97, pp. 130-143. Pitman, London.

Bingham, E. T., and Gillies, C. B. 1971. Can. J. Genet. Cytol. 13, 195-206.

Bingham, E. T., and McCoy, T. J. 1979. Crop Sci. 19, 97-100.

Bingham, E. T., and Saunders, J. W. 1974. Crop Sci. 14, 474-477.

Brewbaker, J. L., and Keim, W. F. 1953. Am. Nat. 83, 323-326.

Broksh, L. L. 1982. Tr. Prikl. Bot., Genet. Sel. 73, 43-49.

Brown, C. R., Salazar, L., Ochoa, C., Chavez, R., Schilde-Rentschler, L., and Lizarraga, C. 1984. EAPR Abstr. Conf. Pap. 9, 288-289.

Buckner, R. C., Burrus, P. B., and Bush, L. P. 1977. Crop Sci. 17, 672-673.

Burk, L. G. 1967. J. Hered. 58, 215-218.

Cauderon, Y. 1978. Interspecific Hybrid. Plant Breed., Proc. Congr. EUCARPIA, 8th, Madrid, 1977 pp. 131-143.

Cauderon, Y. 1979. Proc. Conf. Broadening Genet. Base Crops, Wageningen, 1978 pp. 175-186. Cent. Agric. Publ. Doc., Wageningen.

Chaplin, J. F. 1962. Tob. Sci. 6, 184-187.

Chaplin, J. F., and Mann, T. J. 1961. N.C. Agric. Exp. Stn., Tech. Bull. No. 145.

Chou, M., and Gibson, P. B. 1968. Crop Sci. 8, 266-267.

Clausen, R. E., and Goodspeed, T. H. 1925. Genetics 10, 278-284.

Clayton, E. E. 1947. J. Hered. 38, 35-40.

Cole, K. 1956. Am J. Bot. 43, 794-801.

Company, M., Stalker, H. T., and Wynne, J. C. 1982. Euphytica 31, 385-394.

Cooper, D. C., and Brink, R. A. 1945. Genetics 30, 376-401.

Culp, T. W., and Harrell, D. C. 1973. Crop Sci. 13, 686-689.

Darmency, H., Ouin, C., and Pernes, J. 1987. Genome 29, 453-456.

Darvey, N. L. 1984. Genetics 107, Suppl., 24.

da Silva, F. P., Endrizzi, J. E., Stith, L. S., and Muramoto, H. 1975. Crop Sci. 15, 872-873.

den Nijs, T. P. M., and Peloquin, S. J. 1977a. Euphytica 26, 585-600.

den Nijs, T. P. M., and Peloquin, S. J. 1977b. Am. Potato J. 54, 377-386.

DeVerna, J. W., Mayers, J. R., and Collins, G. B. 1987. Theor. Appl. Genet. 73, 665-671.

de Wet, J. M. J. 1980. In "Polyploidy: Biological Relevance" (W. H. Lewis, ed.), pp. 3-16. Plenum, New York.

Dewey, D. R. 1971. Crop Sci. 11, 575-580.

Dewey, D. R, 1977. Crop. Sci. 17, 803-805.

Dewey, D. R. 1980. In "Polyploidy: Biological Relevance" (W. H. Lewis, ed.), pp. 445-470. Plenum, New York.

Dewey, D. R., and Pendse, P. C. 1968. Crop Sci. 8, 607-611.

Dionne, L. A. 1963. Euphytica 12, 263-269.

Driscoll, C. J., and Jensen, N. F. 1963. Genetics 48, 459-68.

Dvorak, J. 1977. Can. J. Genet. Cytol. 19, 133-147.

Dvorak, J., and Knott, D. R. 1977. Wheat Inf. Serv., Kyoto Univ. Nos. 33/34, pp. 35-37.

Dweikat, I. M., and Lyrene, P. M. 1988. Theor. Appl. Genet. 76, 555-559.

Dyck, P. L., and Kerber, E. R. 1970. Can. J. Genet. Cytol. 12, 175-180.

Ehlenfeldt, M. K., and Hanneman, R. E., Jr. 1988. Theor. Appl. Genet. 75, 825-832.

Evans, A. 1962a. Euphytica.11, 164-176.

Evans, A. 1962b. Euphytica 11, 256-262.

Evans, G. M., and Davies, E. W. 1985. Theor. Appl. Genet. 71, 185-192. 
Forster, B. P., and Dale, J. E. 1983. Ann. Bot. 52, 613-620.

Fuller, J. M., and Howard, H. W. 1974. Ann. Appl. Biol. 77, 121-128.

Gardner, M. E. B., and Stalker, H. T. 1983. Crop Sci. 23, 1069-1074.

Gerechter-Amitai, Z. K., Wahl, I., Vardi, A., and Zohary, D. 1971. Euphytica 20, 281-285.

Gibson, P. B., and Beinhart, G. 1969. J. Hered. 60, 93-96.

Gill, B. S., and Raupp, W. J. 1987. Crop Sci. 27, 445-450.

Gill, R. S., Multani, D. S., and Dhaliwal, H. S. 1986. Crop Improv. 13, 200-203.

Goins, R. B., and Apple, J. L. 1971. Tob. Sci. 15, 7-11.

Goldy, R. G., and Lyrene, P. M. 1984. Euphytica 33, 221-226.

Hadley, H. H., and Openshaw, S. J. 1980. In "Hybridization of Crop Plants" (W. R. Fehar and H. H. Hadley, eds.), pp. 133-159. Am. Soc. Agron.-Crop Sci. Soc. Am., Madison, Wisconsin.

Han, H., and Hangyuan, Y. 1987. "Haploid of Higher Plants In-Vitro." Springer-Verlag, Berlin.

Hanneman, R. E., Jr. 1968. Ph.D. Thesis, Univ. of Wisconsin, Madison.

Hanneman, R. E., Jr., and Peloquin, S. J. 1967. Eur. Potato J. 10, 62-73.

Hanneman, R. E., Jr., and Peloquin, S. J. 1968. Am. Potato J. 45, 255-261.

Hanneman, R. E., Jr., and Peloquin, S. J. 1969. Am. Potato J. 46, 436.

Harlan, J. R., and de Wet, J. M. J. 1975. Bot. Rèv. 41, 361-390.

Havey, M. J., Maxwell, D. P., and Irwin, J. A. G. 1987. Crop Sci. 27, 873-879.

Haynes, F. L. 1972. In "Prospects for the Potato in the Developing World" (E. R. Franch, ed.), pp. 101-110. Int. Potato Cent., Lima, Peru.

Hermsen, J. G. T. 1983. In "Research for the Potato in the Year 2000 " (W. V. Hooker, ed.), pp. 29-32. Int. Potato Cent., Lima, Peru.

Hermsen, J. G. T., and Ramanna, M. S. 1973. Euphytica 22, 457-466.

Hermsen, J. G. T., and Ramanna, M. S. 1981. Philos. Trans. R. Soc. London, Ser. B 292, 499-507.

Hermundstad; S. A., and Peloquin, S. J. 1985. Am. Potato J. 62, 479-487.

Holmes, F. O. 1938. Phytopathology 28, 553-61.

Hougas, R. W., and Peloquin, S. J. 1962. "The Potato and its Wild Relatives," pp. 21-24. Texas Res. Found., Renner, Texas.

Irikura, Y. 1968. Res. Bull. Hokkaido Natl. Agric. Exp. Stn. 92, 23.

Johansen, E. L., and Smith, B. W. 1956. Am. J. Bot. 43, 250-258.

Johnston, S. A., and Hanneman, R. E., Jr. 1978. Am. Potato J. 55, 380.

Johnston, S. A., and Hanneman, R. E., Jr. 1980. Am. Potato J. 57, 7-14.

Johnston, S. A., and Hanneman, R. E., Jr. 1982. Science 217, 446-448.

Johnston, S. A., den Nijs, T. P. M., Peloquin, S. J., and Hanneman, R. E., Jr. 1980. Theor. Appl. Genet. 57, 5-9.

Johnston, T. D. 1974. Euphytica 23, 681-683.

Jong, J. H. de, Speckmann, G. J., Bock, T. S. M. de, Lange, W., and Voorst, A. van. 1986. Can. J. Genet. Cytol. 28, 439-443.

Jung, C., Wehling, P., and Loptien, H. 1986. Plant Breed. 97, 39-45.

Kasha, K. J., and Sadasivaiah, R. S. 1971. Chromosoma 35, 264-287.

Kazimierska, E. M. 1978. Genet. Pol. 19, 15-24.

Kedrov-Zikhman, O. O., Shilko, T. S., and Makarevich, A. P. 1987. Dokl. Akad. Nauk BSSR 31, 368-371.

Keep, E. 1975. In "Advances in Fruit Breeding" (J. Janick and J. N. Moose, eds.), pp. 197-268. Purdue Univ. Press, Lafayette, Indiana.

Kerber, E. R., and Dyck, P. L. 1969. Can. J. Genet. Cytol. 11, 639-647.

Kerber, E. R., and Dyck, P. L. 1973. Can. J. Genet. Cytol. 15, 397-409. 
Kimber, G. 1961. Nature (London) 191, 98-100.

Kimber, G., and Sears, E. R. 1980. In "Polyploidy: Biological Relevance" (W. H. Lewis, ed.), pp. 427-443. Plenum, New York.

King, M. J., Bush, L. P., Buckner, R. C., and Burrus, P. B. 1987. Ann. Bot. 60, 127-132.

Knight, R. L. 1953. J. Genet. 51, 270-275.

Knight, R. L. 1954. Emp. J. Exp. Agric. 22, 68-92.

Knight, R. L., Keep, E., Briggs, J. B., and Porker, J. H. 1974. Ann. Appl. Biol. 76, 123-130.

Knott, D. R. 1961. Can. J. Plant Sci. 41, 109-123.

Knott, D. R. 1968. Can. J. Genet. Cytol. 10, 695-696.

Knott, D. R., and Dvorak, J. 1976. Annu. Rev. Phytopathol. 14, 211-235.

Knowles, R. P. 1955. Can. J. Bot. 33, 534-546.

Kryuchkova, A. F. 1972. Tr. Sredneaziat. Opytn. Stn. VNII Rástenievod. 2, 234-241.

Kummer, M. 1984. Tagungsber., Akad. Landwirtschaftswiss. Dtsch. Dem. Repub. 225, 191-199.

Kuriyama, T., Kuniyasu, K., and Mochizyk, H. 1971. Bull. Hortic. Res. Stn. Jpn., Ser. B No. $11,33-60$.

Kuspira, J., Bhambhani, R. N., and Shimada, T. 1985. Can. J. Genet. Cytol. 27, 51-63.

Ladizinsky, G., and Feinstein, R. 1977. Can. J. Genet. Cytol. 19, 59-66.

Lammaerink, J. 1970. N.Z.J. Agric. Res. 13, 105-110.

Lee, J. A. 1981. J. Hered. 72, 299-300.

Leue, F. F., and Peloquin, S. J. 1981. Am. Potato J. 58, 509.

Lin, B. Y. 1975. Ph.D. Thesis, Univ. of Wisconsin, Madison.

Livermore, J. R., and Johnstone, F. E., Jr. 1940. Am. Potato J. 17, 170-173.

Loptien, H. 1984a. Z. Pflanzenzuecht. 93, 237-245.

Loptien, H. 1984b. Z. Pflanzenzuecht. 92, 208-220.

McHale, N. A., and Lauer, F. I. 1981a. Am. Potato J. 58, 93-102.

McHale, N. A., and Lauer, F. I. 1981b. Am. Potato J. 58, 365-374.

Maheshwari, S. C., Rashid, A., and Tyagi, A. K. 1982. Am. J. Bot. 69, 865-879.

Maizonnier, D. 1972. Ann. Amelior. Plant. 22, 375-387.

Mendiburu, A. O., and Peloquin, S. J. 1977. Theor. Appl. Genet. 49, 53-61.

Mendiburu, A. O., Peloquin, S. J., and Mok, D. W. S. 1974. In "Haploids in Higher Plants: Potentials and Advances"' (K. J. Kasha, ed.), pp. 249-258. 'Univ. of Guelph, Guelph, Ontario.

Mettin, D., Bluthner, W. D., and Schlegel, G. 1973. Proc. Int. Wheat Genet. Symp. 4th, Columbia, Mo.pp. 179-184.

Meyer, J. R. 1957. J. Hered. 48, 249-250.

Meyer, V. G. 1974. Econ. Bot. 28, 56-60.

Mirakhmedov, S. M., Arutyunova, L. G., Babamuratov, K., and Egamberdiev, A. 1985. Sov. Agric. Sci. 1, 5-8.

Mok, D. W. S., and Peloquin, S. J. 1975. Can. J. Genet. Cytol. 17, 217-225.

Moss, J. P. 1980. In "Advances in Legume Science" (R. J. Summerfield and A. H. Bunting, eds.), pp. 525-535. Publ. R. Bot. Gard., Kew, England.

Muller, K. O. 1951. Z. Pflanzenzuecht. 29, 366-387.

Nesling, F. A. V., and Morris, D. A. 1979. Z. Pflanzenphysiol. 91, 345-358.

Nilsson, F. 1973. Jugosl. Vocarstvo 25/26, 37-44.

Nishiyama, I., and Inomata, N. 1966. Jpn. J: Genet. 41, 27-42.

Nishiyama, I., and Yabuno, T. 1979. Cytologia 43, 453-466.

Okwaugwu, C. O., and Peloquin, S. J. 1981. Am. Potato J. 58, 512.

Olsson, G. 1963. In "Recent Plant Breeding Research"' (E. Akerberg, A. Hagberg, G. Olsson, and O. Tedin, eds.), pp. 179-192. Wiley, New York. 
O'Mara, J. G. 1940. Genetics 25, 401-408.

Owuor, J. B. O. 1985. Euphytica 34, 355-360.

Owuor, J. B. O. and van der Vossen, H. A. M. 1981. Euphytica 30, 861-866.

Pandey, K. K. 1975. Nature (London) 256, 311-312.

Pandey, K. K. 1980. Heredity 45, 15-29.

Parrott, W. A., and Smith, R. R. 1986. Can. J. Genet. Cytol. 28, 581-586.

Peloquin, S. J. 1983. In "Research for Potato Breeding in the Year 2000" (W. J. Hooker, ed.), pp. 32-34. Int. Potato Cent., Lima, Peru.

Peloquin, S. J., Hanneman, R. E., Jr., and Johnston, S. A. 1982. Agron. Abstr. p. 79.

Quesenberry, K. H., and Taylor, N. L. 1978. Crop Sci. 18, 551-556.

Rabotyagov, V. D. 1982. Byull. Gl. Bot. Sada No. 123, 69-75.

Raghavan, V. 1986. In "Cell Culture and Somatic Cell Genetics of Plants" (F. Constabel and I. K. Vasil, eds.), Vol. 3, pp. 613-633. Academic Press, San Diego, California.

Raman, V. S. 1976. "Cytogenetics and Breeding in Arachis." Today \& Tomorrow, New Delhi.

Reddick, D., Crosier, W. F., and Mills, W. R. 1931. Proc. Annu. Meet. Potato Assoc. Am. 18, 60-64.

Rick, C. M., and Butler, L. 1956. Avd. Genet. 8, 267-382.

Rick, C. M., DeVerna, W. J., Chetelat, R. T., and Stevens, M. A. 1986. Proc. Natl. Acad. Sci. USA 83, 3580-3583.

Rick, C. M., Chetelat, R. T., and DeVerna, J. W. 1988. Theor. Appl. Genet. 76, 647-655.

Riley, R., and Chapman, V. 1958. Nature (London) 182, 713-715.

Riley, R., Chapman, V., and Johnson, R. 1968. Nature (London) 217, 383-384.

Rubtsov, M. I., and Komkova, T. N. 1983. Skh. Biol. 2, 55-58.

San, L. H., and Gelebart, P. 1986. In "Cell Culture and Somatic Cell Genetics of Plants" (F. Constabel and I. K. Vasil, eds.), Vol. 3, pp. 305-322. Academic Press, San Diego, California.

Sanford, J. C., and Hanneman, R. E., Jr. 1982. Theor. Appl. Genet. 61, 151-159.

Sangduen, N., Kreitner, G. L., and Sovensen, E. L. 1983. Can. J. Bot. 61, 1241-1257.

Sastri, D. C. 1984. Adv. Appl. Biol. 10, 71-111.

Savitsky, H. 1975. Can. J. Genet. Cytol. 17, 197-209.

Schweppenhauser, M. A. 1968. Covesta Inf. Bull. 1, 9-20.

Schwer, J. F., and Cleveland, R. W. 1972a. Crop Sci. 12, 321-324.

Schwer, J. F., and Cleveland, R. W. 1972b. Crop Sci. 12, 419-422.

Sears, E. R. 1956. In "Genetics and Plant Breeding," Brookhaven Symp. Biol., No. 9, pp. 1-22. Brookhaven Natl. Lab., Upton, New York.

Sears, E. R. 1972. Stadler Genet. Symp. 4, $23-28$.

Sears, E. R. 1973. Proc. Int. Wheat Genet. Symp., 4th pp. 191-199.

Sears, E. R., and Okamoto, M. 1958. Proc. Int. Congr. Genet., 10th 2, 258-259.

Shii, C. T., Rabakoarihanta, A., Mok, M. C., and Mok, D. W. S. 1982. Theor. Appl. Genet. 62, 59-64.

Shivanna, K. R. 1982. In "Experimental Embryology of Vascular Plants" (B. M. Johri, ed.), pp. 131-174. Springer-Verlag, Berlin and New York.

Singh, A. K. 1985. Proc. Int. Workshop Cytogenet. Arachis pp. 107-117. ICRISAT Patancheru, Andhra Pradesh, India.

Singh, A. K. 1986a. Theor. Appl. Genet. 72, 164-169.

Singh, A. K. 1986b. Theor. Appl. Genet. 72, 433-439.

Singh, A. K. 1986c. In "Genetic Manipulation in Plant Breeding" (W. Horn, C. J., Jensen, W., Odenbach, and O. Schieder, eds.), pp. 207-209. de Gruyter, Berlin. 
Singh, A. K., and Gibbons, R. W. 1985. In "Advances in Genetics and Crop Improvement"

(P. K. Gupta and J. R. Bahl, eds.), pp. 297-308. Rastogi, Meerut, India.

Singh, A. K., and Moss, J. P. 1982. Theor. Appl. Genet. 61, 305-314.

Singh, A. K., and Moss, J. P. 1984a. Theor. Appl. Genet. 68, 355-365.

Singh, A. K., and Moss, J. P. 1984b. Peanut Sci 11, 17-21.

Singh, A. K., Sastri, D. C., and Moss, J. P. 1980. Proc. Int. Workshop Groundnut pp. 82-90. ICRISAT, Patancheru, Andhra Pradesh, India.

Singh, A. K., Salamini, F., and Uhrig, H. 1989. J. Genet. Breed. 43, 1-5.

Slesaravichyus, A. K., and Dabkyavichene, G. A. 1988. Sel. Semenovod. (Moscow) No 1, 24.

Smartt, J., and Gregory, W. C. 1967. Oleagineux 22, 455-459.

Smartt, J., Gregory, W. C., and Gregory, M. P. 1978. Euphytica 27, 677-680.

Spielman, I. V., Burge, A. P., and Moss, J. P. 1979. Z. Pflanzenzuecht. 83, 236-250.

Stalker, H. T. 1980. Adv. Agron. 33, 111-147.

Stalker, H. T., and Moss, J. P. 1987. Adv. Agron. 41, 1-40.

Stalker, H. T., Wynne, J. C. and Company, M. 1979. Euphytica 28, 675-684.

Stanford, E H., Clement, W. M., Jr., and Bingham, E. T. 1972. In "Alfalfa Science and Technology" (C. H. Hanson, ed.), pp. 87-101. Am. Soc. Agron. Madison, Wisconsin.

Stavely, J. R., Pittarelli, G. W., and Burk, L. G. 1973. J. Hered. 64, 265-271.

Stebbins, G. L. 1950. "Variation and Evolution in Plants." Columbia Univ. Press, New York.

Stebbins, G. L. 1971. "Chromosomal Evolution in Higher Plants." Arnold, London.

Taylor, N. L., Hardin, W. C., Gray, E., and Kendall, W. C. 1959. Agron. Abstr. pp. 67-68.

Taylor, N. L., Stroube, G. E., and Kendall, W. 1963. Crop Sci. 3, 549-552.

Terry-Lewandowski, V. M., and Stimart, P. D. 1985. Euphytica 34, 483-487.

Thomas, H. 1981. Philos. Trans. R. Soc. London, Ser. B 292, 519-527.

Thomas, H., and Al-Ansari, N. 1980. Chromosoma 79, 115-124.

Thomas, H., Leggett, J. M., and Jones, T. T. 1975. Euphytica 24, 717-724.

Thomas, H., Haki, J. M., and Arangzeb, S. 1980a. Euphytica 29, 391-399.

Thomas, H., Powell, W., and Aung, T. 1980b. Euphytica 29, 635-640.

Thomas, H. M., and Pickering, R. A. 1983. Theor. Appl. Genet. 66, 135-140.

Toxopeus, H. J. 1952. Euphytica 1, 133-139.

Trimble, J. P., and Hovin, H. W. 1960. Agron. J. 52, 485.

Valleau, W. D. 1952. Econ. Bot. 6, 69-102.

Valleau, W. D., Stokes, G. W., and Johnson, E. M. 1960. Tob. Sci. 4, 92-94:

Vardi, A. 1970. Heredity 25, 85-91.

Vardi, A. 1974. Heredity 32, 171-181.

Vardi, A., and Zohary, D. 1967. Heredity 22, 541-560.

Vavilova, M. 1975. Kartofel Ovoshchi 10, 7-9.

Veilleux, R. 1983. Plant Breed. Rev. 3, 253-288.

Veilleux, R., and Lauer, F. I. 1981. Euphytica 30, 547-561.

Veilleux, R., Lauer, F. I., and Desborough, S. L. 1981. Euphytica 30, 563-577.

Veronesi, F., Mariani, A., and Bingham, E. T. 1986. Theor. Appl. Genet. 72, 37-41.

Wangenheim, K. H. F., von. 1955. Z. Pflanzenzuecht. 34, 7-48.

Wark, D. C. 1970. Tob. Sci. 171, 141.

Watson, I. A. 1970. In "Genetic Resources in Plants-Their Exploration and Conservation" (O. H. Frankel and E. Bennett, eds.), IBP Handb. No. 11, pp. 441-457. Blackwell, Oxford.

Webster, G. T., and Buckner, R. C. 1971. Crop Sci. 11, 109-112. 
Wenzel, G., Schieder, O., Prezwozny, T., Sopory, S. K., and Melchers, G. 1979. Theor. Appl. Genet. 55, 49-55.

Wernsman, E. A., and Matzinger, D. F. 1966. Crop Sci. 6, 298-300.

Wienhues, A. 1966. Proc. Int. Wheat Genet. Symp., 2nd; Hereditas, Suppl. No. 2, 328-341. Williams, E., and White, D. W. R. 1976. N.Z. J. Bot. 18, 215-220.

Zeller, F. J. 1973. Proc. Int. Wheat Genet. Symp., 4th pp. 209-221.

Zenkteler, M., and Nitzsche, W. 1984. Theor. Appl. Genet. 68, 311-315.

Zeven, A. C., and van Harten, A. M., eds. 1979. Proc. Conf. Broadening Genet. Base Crops, Wageningen, 1978 Cent. Agric. Publ. Doc., Wageningen. 